\title{
Effect of a long-chain n-3 polyunsaturated fatty acid-enriched diet on adipose tissue lipid profiles and gene expression in Holstein dairy cows
}

\author{
Sebastien Elis, ${ }^{* 1}$ Alice Desmarchais, ${ }^{*}$ Sandrine Freret, ${ }^{*}$ Virginie Maillard, ${ }^{*}$ Valérie Labas, ${ }^{*}$ Juliette Cognié, ${ }^{*}$ \\ Eric Briant, $†$ Celine Hivelin, ${ }^{*}$ Joëlle Dupont, ${ }^{*}$ and Svetlana Uzbekova* \\ *UMR PRC, CNRS, IFCE, INRA, Université de Tours, 37380, Nouzilly, France \\ †UE PAO, INRA, 37380, Nouzilly, France
}

\section{ABSTRACT}

The objective of this study was to determine whether fish oil supplement has an effect on adipose tissue lipid profiles and gene expression in postpartum dairy cows. Holstein cows were supplemented with either long-chain n-3 polyunsaturated fatty acid (PUFA; protected fish oil) or control PUFA (n-6; toasted soybeans) for 2 mo after calving $(\mathrm{n}=23$ per diet). These cows showed no difference in milk production or metabolic parameters, but exhibited a tendency toward a decrease in early embryo mortality rate after artificial insemination. We hypothesized that, in addition to this effect, modifications in adipose tissue (AT) gene expression and lipid profiles would occur in response to diet. Subcutaneous AT samples were thus collected from the dewlaps of n-3 and n- 6 dairy cows at 1 mo antepartum, and 1 wk, 2 mo, and 5 mo postpartum for the analysis of lipids and gene expression. Lipid profiles were obtained by matrix-assisted laser desorption/ionization time-offlight mass spectrometry in both positive and negative modes. We found 37 lipid species in the 200 to 1,200 $m / z$ range, which differed between the $\mathrm{n}-3$ and control groups, suggesting that the n-3 supplement affected the lipid composition through the enrichment of lipids integrating long-chain PUFA from fish oil sources: eicosapentaenoic and docosahexaenoic acid. Moreover, a decrease in triacylglycerolipids was observed in AT of n-3 supplemented cows. The expression of 44 genes involved in fatty acid metabolism and the adipokine system was assessed by real-time reverse-transcription PCR. Hierarchical clustering, according to either postpartum stage or diet, enabled us to group genes exhibiting similar kinetic properties during lactation or by those that varied in similar ways after n- 3 supplementation, respectively. Among the genes exhibiting a

Received February 19, 2016.

Accepted August 9, 2016.

${ }^{1}$ Corresponding author: sebastien.elis@tours.inra.fr dietary effect, FABP4, LIPE, CD 36, and PLIN1 were overexpressed in n-3 AT samples compared with the control, suggesting an increase in lipolysis due to n-3 supplementation, which was reflected on lipolytic activity at the protein level (i.e., protein expression of fatty acid binding protein 4 , phosphorylated perilipin 1 , and phosphorylated hormone-sensitive lipase). This increase in lipolysis is relevant to the decrease in triglycerides observed in these samples. Gene expression analyses between n-3 and control AT samples also suggested that the n-3 diet could modulate the secretory functions of AT, possibly by affecting adipokine expression; however, this has to be confirmed at the protein level. Key words: adipose tissue, gene expression, lipid, n-3 polyunsaturated fatty acid, reproduction

\section{INTRODUCTION}

Adipose tissue (AT) metabolism is a key element of successful lactation and reproduction in dairy cows (Wathes et al., 2012). Indeed, AT is now known to be involved in IGF-1 and adipokine production and is consequently important for numerous physiological functions, including immunity, inflammation, energy metabolism (reviewed in Fasshauer and Bluher, 2015), and reproduction (Tersigni et al., 2011).

Dairy cows require enhanced mobilization from body lipid reserves to meet energy requirements at the beginning of lactation. For example, during the first $10 \mathrm{wk}$ of lactation, dairy cows require the mobilization of 15 to $50 \mathrm{~kg}$ of fat, depending on both nutrition and milk yield (McNamara et al., 2003; McNamara and Valdez, 2005; van Straten et al., 2008; Rocco and McNamara, 2013 ; thus, lipolysis is an essential process to provide energy for all biological functions. It is therefore crucial to understand the molecular mechanisms involved in this process more thoroughly. Previous studies using omics technologies have enabled the identification of genes and pathways involved in adipogenesis (Prokesch et al., 2009). Specifically, genes involved in fatty acid 
transport (i.e., $F A B P 4$ ) and genes involved in lipolysis (i.e., LIPE) showed increased expression in AT $1 \mathrm{wk}$ postpartum (1WPP) in dairy cows; however, genes involved in lipogenesis (i.e., $A C A C A, L P L, F A S N$ ) showed decreased expression at this stage (Sumner-Thomson et al., 2011; Elis et al., 2013). Some adipokine genes also showed a modification of expression at this stage: leptin mRNA in AT and plasma adiponectin are decreased at 1WPP (Giesy et al., 2012), whereas resistin mRNA and protein are increased in AT (Reverchon et al., 2014).

The n-3 PUFA are essential fatty acids for mammals and are obtained via diet; n-3 PUFA is a family of biologically active fatty acids. Alpha-linolenic acid (ALA; C18:3) can be converted through a series of desaturation and elongation reactions into other members of the long-chain n-3 PUFA family that have higher biological activity (Simopoulos, 2002; Plourde and Cunnane, 2007): eicosapentaenoic acid (EPA; C20:5) and docosahexaenoic acid (DHA; C22:6; Calder, 2012). Nevertheless, these reactions have a poor efficiency in mammals, thus additional long-chain n-3 PUFA are required from the diet. The n-3 PUFA have a wide range of physiological roles, via interactions with receptors or sensors, or through their presence in the cell membrane (membrane fatty acid composition, membrane order, lipid rafts, and so on; reviewed in Calder, 2012). In cows, an n-3 PUFA-supplemented diet increased the n-3 PUFA composition in plasma (Zachut et al., 2010) and reduced $A C A C A, F A S N, L P L$, and $S C D$ expression in AT (Hiller et al., 2011; Corazzin et al., 2013).

In our previous study, dairy cows were supplemented with a rumen-protected source of n-3 PUFA from calving to 2 mo postpartum (2MPP) and production, metabolic, and reproduction parameters were assessed (Elis et al., 2016). The n-3 PUFA (DHA and EPA) were chosen because these molecules exert pleiotropic effects (Cha et al., 2001) and the conversion rate of ALA into EPA or DHA is low (Simopoulos, 2002). To ensure a specific effect of n-3 PUFA, an n-6 PUFA-enriched diet was chosen as the control. This supplementation $(1 \%$ DM) did not affect the production and metabolic parameters measured [BW, milk yield, milk composition, DMI, energy balance, plasma fatty acids, urea, and glucose levels], but affected fertility with a tendency to decrease nonfertilization or early embryo mortality rate after the first AI (Elis et al., 2016).

The objective of the present study was to assess whether supplementation with n-3 PUFA would affect gene expression and lipid profiles in subcutaneous AT during lactation from samples collected before, during, and after dietary supplementation from the cows previously analyzed for metabolic and fertility parameters (Elis et al., 2016). We hypothesized that diet would induce changes in gene expression and lipid profiles in AT and looked at these changes in terms of energy supply or AT secretory functions. Therefore, the expression of 44 genes, including those involved in lipid metabolism functions, adipokines, insulin, inflammatory pathways, or cell signaling was investigated by real time reverse transcription (RT)-PCR. Adipose tissue lipid profiles were determined by matrix-assisted laser desorption/ ionization time-of-flight (MALDI-TOF) mass spectrometry to find differentially abundant lipid species between n-3 and control n- 6 supplementation groups through the peripartum period.

\section{MATERIALS AND METHODS}

\section{Animals and Experimental Design}

All experimental protocols were approved by the local ethics committee on animal experimentation (Comité d'Ethique en Expérimentation Animale Val de Loire, Tours, France, protocol registered under ref. 2012-01-1), in accordance with the European Directive 2010/63/EU on the protection of animals used for scientific purposes. Twenty-five Holstein dairy cows were managed in loose housing and monitored over 2 consecutive years in the same experimental dairy herd in a switchback design, as described in Elis et al. (2016). Each cow received either n-3 or control n-6 supplementation in the first year and the other diet in the following year. For the first year of the experiment, cows were either in their first $(\mathrm{n}=7$, with 6 cows in the $\mathrm{n}-3$ diet and 1 cow in the $\mathrm{n}-6$ diet) or second $(\mathrm{n}=$ 18 , with 7 cows in $n-3$ diet and 11 cows in the n- 6 diet) lactation. During the following year of the experiment, $21 / 25$ cows were monitored (4 cows were eliminated from the experiment because they never expressed heat, had a pregnancy failure, or suffered an udder problem) and were either in their second $(\mathrm{n}=6$, with 1 cow in the n- 3 diet and 5 cows in the n- 6 diet) or third $(\mathrm{n}=15$, with 9 cows in $\mathrm{n}-3$ diet and 6 cows in the $\mathrm{n}-6$ diet) lactation. At the end of the experiment, complete data sets could be obtained from a total of 23 cows receiving the $\mathrm{n}-3$ diet and a total of 23 cows receiving the n-6 diet (Supplementary Figure S1A; http://dx.doi. org/10.3168/jds.2016-11052).

\section{Experimental Diets}

The composition of the 2 experimental diets was balanced for energy and protein contents (Table 1); the 2 diets were TMR. The n-3 PUFA supplement (n-3 diet) was a rumen-protected encapsulated fish oil OMG750 (Kemin, Nantes, France) and, as the regular confined dairy cow diet is usually rich in n-6 PUFA (i.e., from either corn or soy), the chosen control was an n-6 
Table 1. Ingredients composing the experimental diets, and nutritional composition of the diets (mean \pm SEM, $\mathrm{n}=3$ samples)

\begin{tabular}{|c|c|c|}
\hline \multirow[b]{2}{*}{ Item } & \multicolumn{2}{|c|}{$\begin{array}{l}\text { Diet from calving } \\
\text { to } 2 \text { mo postpartum }\end{array}$} \\
\hline & n-3 PUFA & $\begin{array}{l}\text { Control n-6 } \\
\text { PUFA }\end{array}$ \\
\hline \multicolumn{3}{|l|}{ Ingredient ( $\%$ of $\mathrm{DM})$} \\
\hline Corn silage & 65.7 & 65.1 \\
\hline Dehydrated alfalfa & 8.3 & 8.3 \\
\hline Sandifort ${ }^{1}$ (wheat) & 10.3 & 10.2 \\
\hline Sandilait $^{1}$ (soybean and rapeseed meal) & 13.7 & 13.6 \\
\hline Vitamins and minerals $5 / 23^{1}$ & 0.6 & 0.6 \\
\hline Calcium bicarbonate & 0.4 & 0.4 \\
\hline Encapsulated fish oil & 1 & - \\
\hline Toasted soybeans & - & 1.8 \\
\hline \multicolumn{3}{|l|}{ Composition } \\
\hline DM $(\%)$ & $38.8 \pm 1.6$ & $38.4 \pm 1.3$ \\
\hline $\mathrm{NE}_{\mathrm{L}}(\mathrm{MJ} / \mathrm{kg}$ of $\mathrm{DM})$ & $6.9 \pm 0.1$ & $7.0 \pm 0.1$ \\
\hline $\mathrm{PDIE}^{2}(\mathrm{~g} / \mathrm{kg}$ of DM $)$ & $91.3 \pm 4.0$ & $88.9 \pm 4.4$ \\
\hline $\mathrm{PDIN}^{2}(\mathrm{~g} / \mathrm{kg}$ of DM) & $89.0 \pm 6.6$ & $86.1 \pm 7.5$ \\
\hline $\mathrm{NDF}(\%)$ & $32.0 \pm 1.0$ & $32.0 \pm 1.4$ \\
\hline $\mathrm{ADF}(\%)$ & $20.8 \pm 0.7$ & $20.5 \pm 0.9$ \\
\hline $\mathrm{CP}(\%)$ & $12.8 \pm 0.9$ & $12.3 \pm 1.0$ \\
\hline Fat $(\%)$ & $2.8 \pm 0.2$ & $2.7 \pm 0.1$ \\
\hline
\end{tabular}

${ }^{1}$ Sandifort and Sandilait (Agralys Thoreau, Ladon, France); vitamins and minerals $5 / 23$ (5\% phosphorus, $23 \%$ calcium).

${ }^{2} \mathrm{PDIE}=$ intestinal digestible proteins, when energy is the limiting factor of microbial synthesis; PDIN = intestinal digestible proteins, when degraded $\mathrm{N}$ is the limiting factor of microbial synthesis.

PUFA supplement (n-6 diet): toasted soybeans Danex (Agralys, Blois, France).

The supplements were manually mixed into the diet (at 1\% DM for the n-3 diet and at 1.8\% DM for the $\mathrm{n}-6$ diet) and the TMR were distributed twice daily from calving to $2 \mathrm{MPP}$. From $2 \mathrm{MPP}$ to 5 mo postpartum (5MPP), cows from both groups received the same diet as follows (all quantities are \% DM): $68 \%$ corn silage, $8 \%$ dehydrated alfalfa, $11 \%$ Sandifort (wheat, Agralys Thoreau, Ladon, France), 12\% Sandilait (soybean and rapeseed meal, Agralys Thoreau), 0.4\% vitamins and minerals 5/23 (5\% phosphorus and $23 \%$ calcium, Agralys Thoreau), and 0.5\% calcium bicarbonate. Cows were fed ad libitum.

\section{Zootechnical Parameters}

As previously described (Elis et al., 2016), BW and milk yield (MY) were monitored daily during the milking period, from calving to 5MPP; DMI and energy balance (EB, expressed in Mcal/d) were analyzed daily during the distribution of the n-3 or n- 6 diets, from calving to $2 \mathrm{MPP}$. Plasma fatty acids were determined using enzymatic colorimetry on a multiparameter analyzer (KONE Instruments Corporation, Espoo, Finland) from plasma samples collected once a week from a caudal venipuncture before diet distribution, from 1 month antepartum (1MAP) to 5MPP. Adipose tissue mobilization was assessed through subcutaneous fat thickness measurements in the sacral region using ultrasonographic examination at 1MAP, 2 wk postpartum, 1 mo postpartum, 2MPP, and 5MPP (Table 2).

\section{AT Sample Collection}

During both lactation periods of the experiment, biopsies of adipose tissue were collected from each animal at 1MAP, $1 \mathrm{WPP}, 2 \mathrm{MPP}$, and 5MPP (total 184 biopsies). Cows were fasted for $12 \mathrm{~h}$ before surgery and blood samples for metabolic measurement were collected on the day of the biopsy. Subcutaneous fat was collected under the neck in the area of the superficial pectoral muscle upstream of the brisket and the forelimbs (dewlap). After sedation with intravenous injections of 12 to $14 \mathrm{mg}$ of xylazine (Rompun, Bayer, Leverkusen, Germany), the area was shaved. Local

Table 2. Estimated means (LSM) of zootechnical parameters ${ }^{1}$

\begin{tabular}{|c|c|c|c|c|c|c|c|c|c|}
\hline \multirow[b]{2}{*}{ Item } & \multirow[b]{2}{*}{$\begin{array}{l}\text { PUFA } \\
\text { diet }\end{array}$} & \multicolumn{7}{|c|}{ Week postpartum or stage ante/postpartum } & \multirow[b]{2}{*}{ SEM } \\
\hline & & $\begin{array}{c}-4 \\
\text { (1 mo antepartum) }\end{array}$ & 1 & $\begin{array}{c}4 \\
\text { (1 mo postpartum) }\end{array}$ & $\begin{array}{c}8 \\
\text { (2 mo postpartum) }\end{array}$ & 12 & 16 & $\begin{array}{c}20 \\
(5 \text { mo postpartum })\end{array}$ & \\
\hline $\mathrm{BW}(\mathrm{kg})$ & $\mathrm{n}-6$ & & 622.8 & 575.0 & 569.6 & 579.0 & 596.5 & 603.3 & 10.7 \\
\hline \multirow[t]{2}{*}{ MY (L/d) } & $\mathrm{n}-3$ & & 22.9 & 35 & 34.7 & 34.2 & 33.9 & 32.4 & 1.2 \\
\hline & $\mathrm{n}-6$ & & 24.9 & 34.8 & 35.9 & 35.5 & 35.3 & 34.7 & 1.1 \\
\hline \multirow[t]{2}{*}{ DMI $(\mathrm{kg} / \mathrm{d})$} & $\mathrm{n}-3$ & & 11.5 & 13.4 & 14.9 & & & & 0.7 \\
\hline & $\mathrm{n}-6$ & & 11.4 & 14.0 & 16.0 & & & & 0.7 \\
\hline \multirow[t]{2}{*}{ EB $($ Mcal/d) } & $\mathrm{n}-3$ & & -7.78 & -12.90 & -10.42 & & & & 1.06 \\
\hline & $\mathrm{n}-6$ & & -9.20 & -11.82 & -9.74 & & & & 1.09 \\
\hline \multirow[t]{2}{*}{ AT thickness } & n-3 & 0.87 & & 0.42 & 0.23 & & & 0.25 & 0.05 \\
\hline & $\mathrm{n}-6$ & 0.78 & & 0.48 & 0.26 & & & 0.21 & 0.05 \\
\hline
\end{tabular}

${ }^{1} \mathrm{MY}=$ milk yield; $\mathrm{FA}=$ plasma fatty acids; $\mathrm{EB}=$ energy balance; $\mathrm{AT}=$ adipose tissue. 
anesthesia was obtained by injection of $200 \mathrm{mg}$ of lidocaine (Lurocaïne, Vetoquinol, Lure, France). The site was disinfected with povidone-iodine (Vétédine, Vetoquinol) and alcohol. A 10-cm incision was made with a scalpel. Subcutaneous tissues were gently dissected to isolate $2 \mathrm{~cm}^{3}$ of fat. The fat was then cut and a gauze compress was placed in the hole: this was left in position appropriate to obtain hemostasis. The site was closed by a subcutaneous and a cutaneous stitch. Samples were immediately frozen in liquid nitrogen and stored at $-80^{\circ} \mathrm{C}$ until use.

\section{AT mRNA Extraction, Real Time RT-PCR, and Hierarchical Clustering}

Total RNA was extracted from $200 \mathrm{mg}$ of adipose tissue and digested with DNase using Nucleospin RNA Midi kit (Macherey-Nagel, Hoerdt, France) according to the manufacturer's instructions. The RNA quantity was assessed using a NanoDrop ND-1000 Spectrophotometer (Nyxor Biotech, Paris, France) and RNA quality was checked on an Agilent 2100 Bioanalyzer using an RNA 6000 Nano assay protocol (Agilent Technologies, Massy, France). Reverse transcription was performed on $1 \mu \mathrm{g}$ of total RNA extracted from adipose tissue using Moloney Murine Leukemia Virus reverse transcriptase I with an oligo dT primer mix (Promega, Madison, WI) according to the manufacturer's instructions. Specific sets of primer pairs (Sigma Genosis, Birmingham, UK) were designed using Primer3Plus software (Rozen and Skaletsky, 2000) to amplify fragments of 44 different transcripts (Supplementary Table S1; http://dx.doi. org/10.3168/jds.2016-11052). Real-time PCR reactions had a total volume of $20 \mu \mathrm{L}$ and contained primers at a final concentration of $150 \mathrm{nM}$ for each, $5 \mu \mathrm{L}$ of the RT reaction diluted 1/30 (30 ng of cDNA), and qPCR Mastermix Plus for Sybr Green I (Bio-Rad, Marnes-la-Coquette, France) according to the manufacturer's instructions. Real-time PCR was performed using a CFX96 (Bio-Rad). The geometric mean of 3 housekeeping genes (RPL19, RPS9, and PPIA) was used to normalize gene expression (the expression of these genes did not vary depending on the sampling period). The relative amounts of gene transcripts (R) were calculated according to the equation:

$$
\mathrm{R}=\frac{\mathrm{E}_{\text {gene }}^{-\mathrm{Ct}_{\text {gene }}}}{\left[\text { geometric mean }\left(\mathrm{E}_{\text {PPIA }}^{-\mathrm{Ct} \text { PPIA }}, \mathrm{E}_{\mathrm{RPS} 9}^{-\mathrm{Ct}_{\mathrm{RPS} 9}}, \mathrm{E}_{\mathrm{RPL} 19}^{-\mathrm{Ct}}\right)\right]},
$$

where $\mathrm{Ct}$ is the cycle threshold and $\mathrm{E}$ is the PCR efficiency for each primer pair (Supplementary Table S1; http://dx.doi.org/10.3168/jds.2016-11052).
The hierarchical classification of PCR data was performed with the Cluster 3.0 software (Stanford University, Stanford, CA) using supervised average linkage clustering with a Euclidian distance analysis (Eisen et al., 1998). To confirm the clustering, Pearson correlations were calculated to determine whether genes that belonged to the same cluster also had positively correlated expression.

\section{Lipid Profiling of AT by MALDI-TOF Mass Spectrometry}

After Folch extraction ( $\mathrm{n}=19$ samples for each diet group; Folch et al., 1957), $1 \mu \mathrm{L}$ of lipid extract from AT (2MPP) was spotted onto an MTP Ground Steel 384 MALDI sample plate (Bruker Daltonics, Billerica, MA) and overlaid with $1 \mu \mathrm{L}$ of a 2,5-dihydroxybenzoic acid/ aniline liquid ionic matrix. The liquid ionic matrix was prepared by adding 1 equivalent of organic base to a solution containing $20 \mathrm{mg} / \mathrm{mL}$ of 2,5-dihydroxybenzoic acid (1 equivalent) in 90\% methanol/9.8\% $\mathrm{H}_{2} 0 / 0.2 \%$ trifluoroacetic acid. The sample and the matrix (1:1, $\mathrm{vol} / \mathrm{vol}$ ) were loaded on the target using the dried droplet method. For each sample, 9 spots were prepared and spectra were acquired twice consecutively per spot (a total of 18 spectra/sample). Lipid profiles were acquired using an ultrafleXtreme MALDI-TOF/ TOF instrument (Bruker Daltonics) equipped with a Smartbeam laser at a $2-\mathrm{kHz}$ laser repetition rate following an automated method controlled by FlexControl 3.0 software (Bruker Daltonics). Spectra were obtained in positive and negative reflection ion mode in the 100 to $1,200 \mathrm{~m} / z$ range and collected from each spot as a sum of 1,000 laser shots in 5 shot steps (total of 5,000 spectra per spot). The parameters used for spectra acquisition were: ion source $1=+25.23 /-20.18 \mathrm{kV}$; ion source $2=+22.45 /-18.04 \mathrm{kV}$; lens $=+8.01 /-6.70 \mathrm{kV}$; pulsed ion extraction at $120 \mathrm{~ns}$; and laser parameter set at medium for positive and negative modes. External calibration was followed using a homemade calibrant solution $(1 \mu \mathrm{L}$ of calibrant solution plus $1 \mu \mathrm{L}$ of matrix) containing caffeine, 4 amino acid MRFA peptide (methionine, arginine, phenylalanine, and alanine), bradykinin 2-9, bradykinin, angiotensin I, and Glu1fibrinopeptide B at $2 \mathrm{pmol} / \mu \mathrm{L}$. A quadratic calibrant algorithm was applied to obtain deviation $<0.0011 \%$.

FlexAnalysis version 3.4 (Bruker Daltonics) was applied to data to extract txt files. Spectra were integrated in Progenesis MALDI version 1.2 (Nonlinear Dynamics, Newcastle upon Tyne, UK). Spectra were processed with baseline subtraction (Top Hat filter 60), denoising (Noise filter 4), and spectra alignment steps to maximize correlations. Automatic peak detection 
was applied to the reference spectrum (a weighted average of all experimental spectra) in the range of 200 to $1,200 \mathrm{~m} / z$ with a threshold fixed at 150 counts. Thus, peaks were detected with a signal/background noise $>2$. Normalization on peak height was performed using the total ionic count to display and compare all spectra on the same scale.

We created 1 average sample spectrum from each set of the 9 replicates to take into account any technical variations. The reproducibility linked directly to the spectrometer process was evaluated by the coefficient of variation $(\mathbf{C V})$ of the 2 average spectra for 3 samples. The CV values were found to range from 4.95 to $19.55 \%$ in the positive mode and 9.32 to $16 \%$ in the negative mode according to all peak values. Mean CV values were $12.39 \pm 7.3 \%$ and $12.49 \pm 3.35 \%$ for the positive and negative modes, respectively. Annotation of lipid species was performed through interrogation of the LipidMaps database (http://www.lipidmaps.org/ tools/ms/LMSD_search_mass_options.php).

\section{Western Blot Analysis}

Proteins were extracted from AT and Western blotting was performed as previously described (Elis et al., 2013). Protein extracts (10 $\mu \mathrm{g} /$ lane) were separated by electrophoresis on 4 to $12 \%$ acrylamide gel (Life technologies, Saint-Aubin, France). Rabbit monoclonal antibody to human fatty acid binding protein 4 (FABP4, D25B3) and polyclonal antibodies to human hormone-sensitive lipase (HSL) and to mouse phosphorylated HSL (phospho HSL Ser660) were obtained from Cell Signaling Technology (Ozyme, Saint Quentin Yvelines, France). Mouse monoclonal antibody to human phosphorylated perilipin 1 (PLIN1, Ser522) (Ser522) was obtained from Valasciences (Valasciences, San Diego, CA). Mouse monoclonal antibody to human PLIN1 (G2) was obtained from Santa Cruz Biotechnology (Dallas, TX). Mouse monoclonal antibody to human vinculin (VCL clone hVIN-1) was purchased from Sigma-Aldrich (St. Louis, MO). The horseradish peroxidase-conjugated antirabbit and antimouse IgG were purchased from Perkin Elmer (Courtaboeuf, France). The signal of specific bands, detected by ECL (West Dura; Thermo Fisher Scientific, Waltham, MA), was quantified using a charge-coupled device camera GeneGnome (Syngene, Cambridge, UK) with Genesys 1.5.4 software (Syngene), and the analysis of signal intensity was performed with GeneTools 4.01 software (Syngene). Results of FABP4, PLIN1, and HSL protein expression are expressed as the ratio to the reporter protein VCL. Results of PLIN1 and HSL phosphorylation are presented as the ratio of phosphorylated protein to total protein. The number of AT samples analyzed by Western blot was 19 for n-3 diet and 14 for control n-6 diet AT samples.

\section{Statistical Analysis}

For the comparison of lipid profiles between the groups ( $\mathrm{n}=19$ samples for each diet group), normalized mass to charge peak height values of each peak were compared using Student's $t$-tests from the average sample spectra, separately for positive and negative modes. The significance threshold was $P<0.05$, which was considered significant. A principal component analysis was performed on the 37 most differential peaks, 22 in the positive mode and 15 in the negative mode $(P<$ 0.05 , fold change $>1.5$ or $>0.75$ ), using XLSTAT 3.01 (Addinsoft, Paris, France).

Gene expression was analyzed using a linear mixed model for repeated measurements [MIXED procedure of the SAS software (SAS institute Inc., 2011)], as previously described for zootechnical parameters, plasma fatty acids, and subcutaneous AT thickness (Elis et al., 2016). Concerning the parameters BW, MY, DMI, and $\mathrm{EB}$, the model included the effects of year of experiment, diet, week postpartum and all interactions, with week postpartum as a repeated effect within cow (year) with an $\mathrm{AR}(1)$ covariance structure and the value of BW at WPP1 as a co-variable for MY and DMI.

For plasma fatty acids, the model included the effects of year of experiment, diet, week ante- or postpartum, and all interactions, with WPP as a repeated effect within cow (year) with a $\mathrm{AR}(1)$ covariance structure and with the value of the WPP-4 (wk 4 antepartum) as a co-variable. For subcutaneous adipose tissue thickness and gene expression, the model included the effects of year of experiment, diet, stage ante- or postpartum and all interactions (with the subcutaneous adipose tissue thickness value at $1 \mathrm{MAP}$ as a co-variable for subcutaneous adipose tissue thickness), and with stage ante- or postpartum as a repeated effect within cow (year) with a CS covariance structure. Least squares means were estimated by the models and subsequently compared using a Student's $t$-test.

As a parity effect could not be included in the model because of the unbalanced design within year and within diet group concerning that criterion (see Animals and Experimental Design section), we also compared parities within year or diet (comparison of parity 1 versus parity 2 cows in year $1 / \mathrm{n}-3$ diet, and comparison of parity 2 versus parity 3 cows in year $2 / \mathrm{n}-6$ diet) to check whether a potential diet effect observed in the global analysis could be confounded with a parity effect.

Pearson correlations (CORR procedure of the SAS software) were calculated between mRNA expression levels of the 44 studied genes (on data from all stages 
and both diets), and between mRNA expression levels of those genes and plasma EPA and DHA concentrations (on data from 1WPP and both diets). Western blotting data were analyzed using a nonparametric Wilcoxon bivariate test using the $\mathrm{R}$ software ( $\mathrm{R}$ Core Team, 2015).

\section{RESULTS}

Analysis of metabolic parameters and subcutaneous AT biopsies were performed on 2 groups of Holstein dairy cows during 2 lactations at 4 different stages ante- or postpartum: 1MAP, before n- 3 or $n-6$ diet; 1WPP, 1 wk after the beginning of the n- 3 or $n-6$ diet; $2 \mathrm{MPP}$, end of the n-3 or n- 6 diet; and 5MPP. As previously reported, there was a significant increase in plasma EPA and DHA at $1 \mathrm{WPP}$ and $2 \mathrm{MPP}$ in the n-3 diet group (Elis et al., 2016). The n-3 diet had no effect on BW, MY, DMI, EB, and subcutaneous AT thickness throughout the 1MAP to 5MPP period studied (Supplementary Figure S1 B-F; http://dx.doi. org/10.3168/jds.2016-11052). However, it is important to note that body fat mobilization is high in our conditions regarding the moderate milk yield, because of the low DMI observed (associated with the low percentage of DM in the diets) compared with other studies (Patton et al., 2007; Sumner-Thomson et al., 2011; Khan et al., 2013; Galamb et al., 2016). Plasma fatty acid profiles were also similar between the n-3 and n- 6 groups (Supplementary Figure S1G). Analysis of lipid composition and gene expression in AT is described in the present work.

\section{Mass Spectrometry Analysis of AT Lipid Composition After 2 mo of $n$-3 Supplementation}

Mass spectrometry analyses provided spectra obtained in positive and negative modes in the 100 to $1,200 \mathrm{~m} / \mathrm{z}$ range (Figure $1 \mathrm{~A}$ ). Spectra are composed of peaks corresponding mostly to lipid molecular species. Lipid profiles obtained by MALDI-TOF mass spectrometry from AT samples of $19 \mathrm{n}$-3-fed cows were compared with those from 19 control (n-6)-fed cows at 2MPP. The AT lipid spectra obtained in the negative mode exhibited 276 peaks between 200 to $1,200 \mathrm{~m} / z$. Among those peaks, 71 showed differential intensity between n-3 and n- 6 samples and 15 had a fold change either $>1.5$ or $<75$. Lipid spectra obtained in the positive mode exhibited 321 peaks between 200 to $923 \mathrm{~m} / z$. Among those peaks, 43 were different between n-3 and n- 6 groups and 22 had a fold change of either $>1.5$ or $<0.75$.

We identified 28 lipids with differential peaks $(P<$ $0.05)$; that is, exhibiting a fold change either $>1.5$ or
$<0.75$ and a peak height intensity $>50$ (21 peaks in positive mode and 7 peaks in negative mode; Table $3)$. The 28 differential peaks ranged from 200 to 910 $m / z$ (Figure 1B). High-mass lipids (895.8, 907.8, and $909.8 \mathrm{~m} / z$, triacylglycerols) were more abundant in AT samples of n-6-supplemented cows, whereas low-mass lipids (214.0, 235.8, 273.1, and $334.1 \mathrm{~m} / z$, fatty acyl lactone, diacylglycerophosphates, hydroxy fatty acids, and monoacylglycerophosphocholines, respectively) were more abundant in AT samples of the n-3 diet group. Annotations of detected lipid ions (Supplementary Table S2; http://dx.doi.org/10.3168/jds.2016-11052) suggest that the high-mass lipids $(895.8,907.8$, and $909.8 \mathrm{~m} / \mathrm{z}$ ) correspond to triacylglycerols (TAG $54: 9+\mathrm{Na}^{+}$, TAG $54: 3+\mathrm{Na}^{+}$, and TAG 54:2+ $\mathrm{Na}^{+}$, respectively).

Other high-mass lipids $(774.5,802.5$, and $852.5 \mathrm{~m} / \mathrm{z}$ ), that were overrepresented in AT of n-3 diet cows could correspond to glycerophospholipids, composed in part of 20:5 or 22:6 n-3 PUFA. Low-mass lipids (214.0, 235.9, 273.1 , and $334.1 \mathrm{~m} / \mathrm{z}$ ) could correspond to either fatty acyls or monoacylglycerophosphocholine.

A principal component analysis was performed on the 37 most differential peaks in both modes (Figure 2 ). This analysis was able to distinguish n-3 from $n-6$ AT samples. Therefore, in dairy cows, 2 mo of n-3 and n-6 PUFA diets at the beginning of lactation led to significant differences in AT lipid species proportion and composition.

\section{Kinetics of AT Gene Expression During Lactation}

To investigate the kinetics of gene expression in AT, we measured the transcript level of 44 genes encoding adipokines and genes involved in lipid metabolism at 1MAP, 1WPP, 2MPP, and 5MPP (Table 4). To group genes with similar dynamic expression patterns, a supervised hierarchical clustering was performed with the control (n-6) samples arranged according to the physiological stage (1MAP, 1WPP, 2MPP, and 5MPP; Figure 3A). Four different clusters exhibiting a high threshold $(>0.7)$ were distinguished. Cluster 1 was composed of 9 genes overexpressed at 1MAP compared with other stages (ACACA, ADIPOQ, APLN, FASN, FFAR 4, LEP, LPL, RBP4, and SCD1; Figure 3B shows relative expression of $S C D 1$ ). All 9 genes, except $A D I P O Q$, had a significant stage effect. Cluster 2 was composed of 8 genes overexpressed at $1 \mathrm{WPP}$ compared with other stages (ADIPOR1, ADIPOR2, CHEMR23, DGAT1, FFAR2, FOXO, PLIN2, and PNPLA2). Only FOXO (Figure 3B) had a significant stage effect, but 2 more genes followed the same tendency (ADIPOR2, $P=0.056$, and PNPLA2, $P=0.066$ ). Cluster 3 was composed of 13 genes overexpressed at both 1WPP and 2MPP (Figure 3A) compared with other stages 
(APPL1, CD36, CPT1A, FABP4, LIPE, NAMPT, PLIN1, PPARD, PPARG, PTEN, PTGS2, RARRES2, and $R E T N)$. Six of these genes had a significant stage effect $[C D 36$ (Figure 3B), FABP4, LIPE, PLIN1, RARRESR, and RETN] and 1 gene followed the same tendency ( $C P T 1 A, P=0.080$ ). Cluster 4 was composed of 12 genes overexpressed at 2MPP and 5MPP (Figure $3 \mathrm{~A})$ compared with other stages (APPL2, ELOV1, FFAR1, FFAR3, GPR84, INSR, LEPR, NFkB, PAI, PPARA, ROR1, and TLR4). Five of these genes had a significant diet effect (ELOV1, FFAR3, INSR, PPA$R A$, and ROR1; Figure $3 \mathrm{~B}$ ) and 2 genes followed the same tendency (APPL2, $P=0.065$, and $L E P R, P=$
$0.064)$. Of the 2 genes that did not belong to any cluster (CPT2 and SREBP1), SREBP1 had a significant stage effect and was overexpressed in 1MAP samples compared with other stages. The dynamic variation of gene expression in AT throughout lactation was similar in n-3 and n-6 diet groups, as no significant interaction between stage and diet effect was observed.

\section{Diet Effect on AT Gene Expression}

To group genes with similar expression patterns in AT samples during the supplementation period, we performed a supervised hierarchical clustering of our data

A.

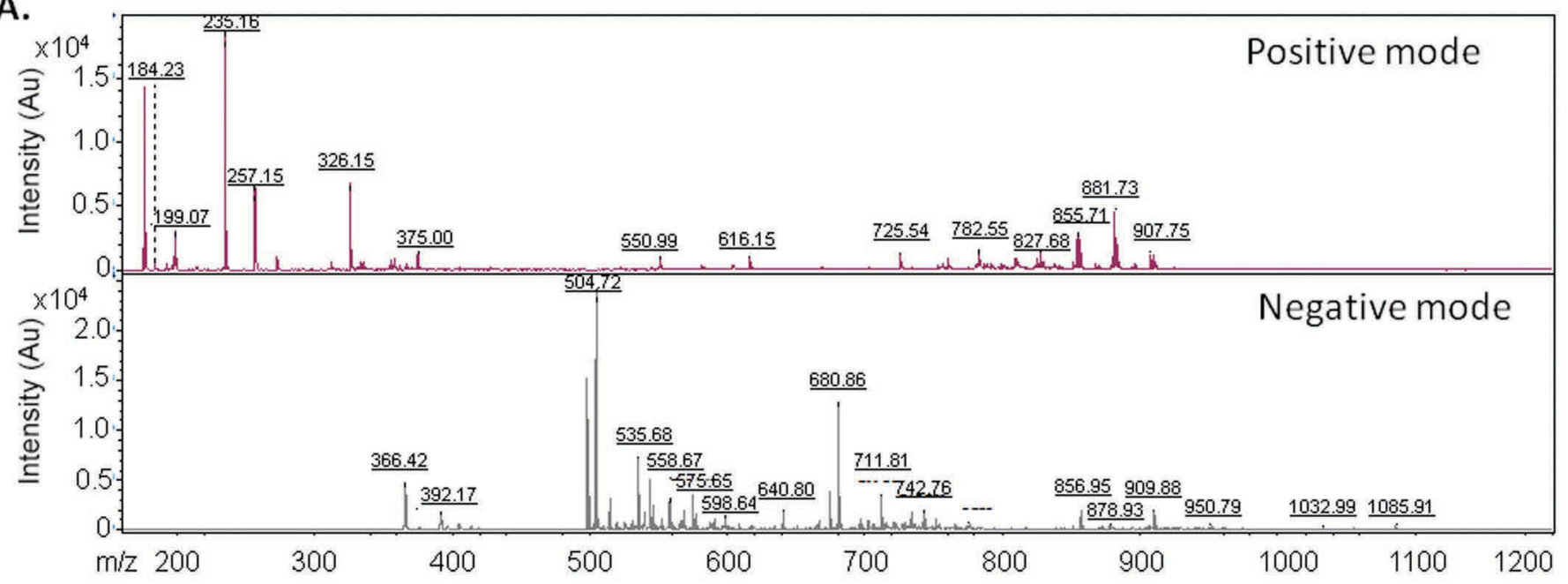

B.

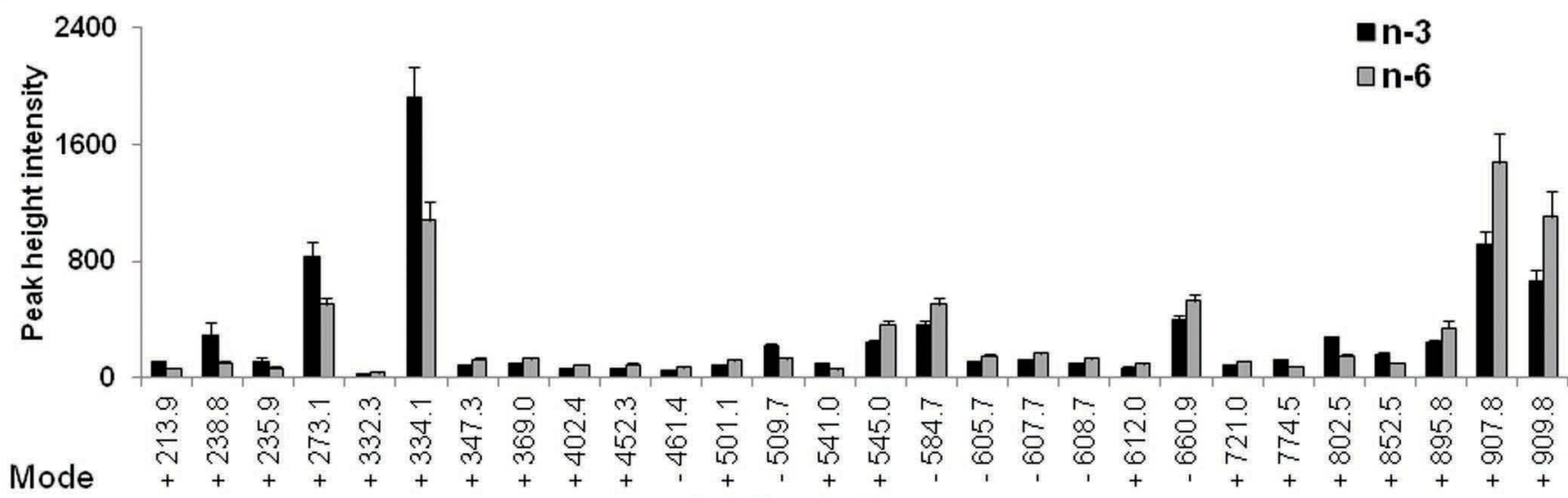

Lipid ions $(\mathrm{m} / \mathrm{z})$

Figure 1. Effect of n-3 diet on dairy cow adipose tissue matrix-assisted laser desorption/ionization time-of-flight (MALDI-TOF) mass spectrometry profiling of lipid extract at 2 mo postpartum. (A) Representative lipid profiles from 1 extract obtained by MALDI-TOF in positive and negative modes from 100 to $1,200 \mathrm{~m} / z$. The MALDI-TOF mass spectrometry analyses were performed after Folch extraction of subcutaneous adipose tissues collected at 2 mo postpartum after the $\mathrm{n}-3$ or $\mathrm{n}-6$ diet in both positive and negative modes ( $\mathrm{n}=19$ for each diet). Peaks correspond to specific mass and therefore to specific lipid species. (B) Differential peaks between n-3 and n- 6 adipose tissues characterized by quantitative MALDI analysis from lipid profiles obtained in positive and negative modes. The 28 most differential species among the main lipids between the n-3 and n- 6 diet (18 technical replicates in each mode, $\mathrm{n}=19$ for each diet), $P<0.05$, fold change $>1.5$ or $<0.75$, and height intensity $>50$ are presented as normalized peak intensity \pm SEM. Color version available online. 
ELIS ET AL.

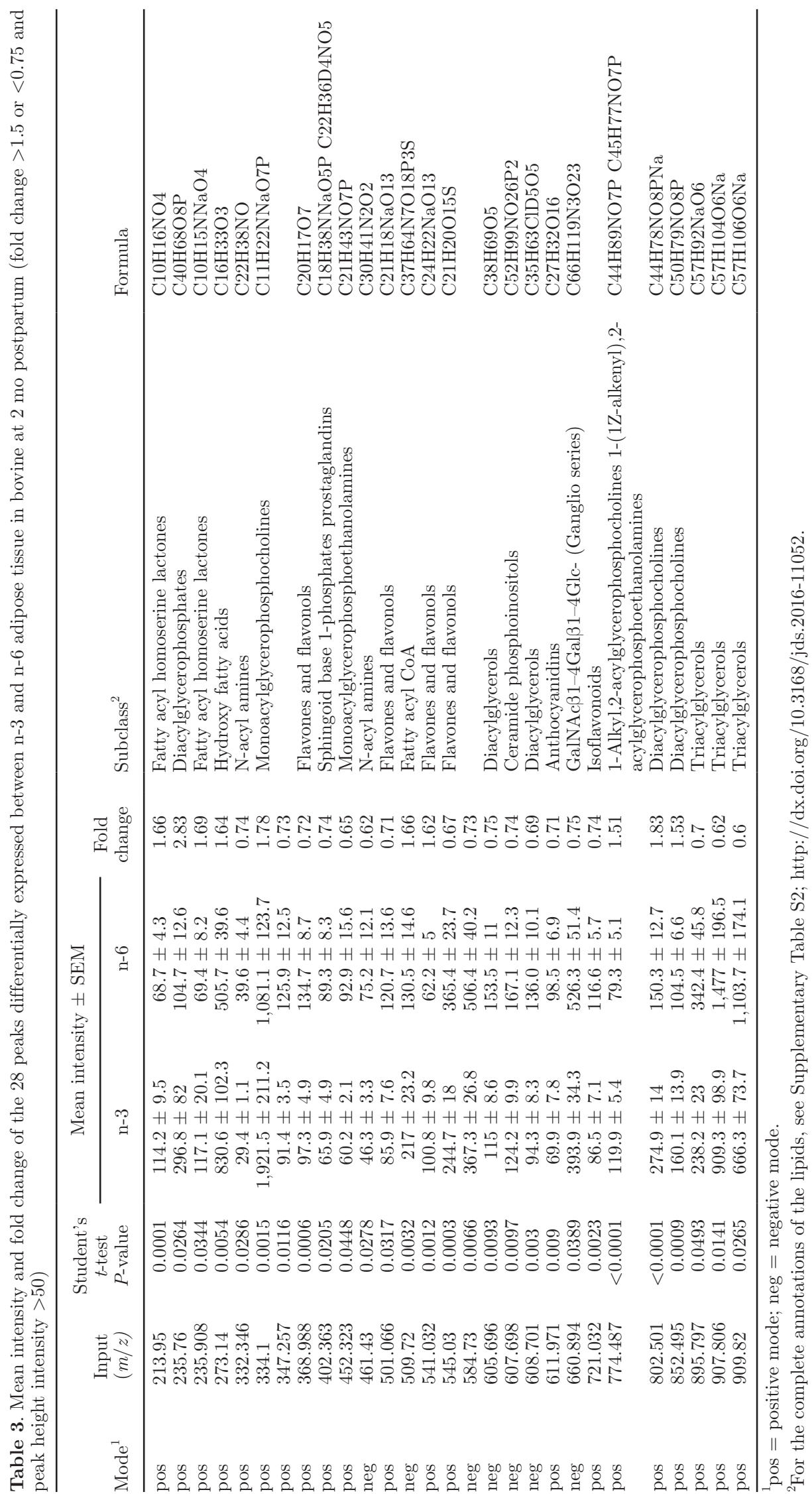


with samples arranged first according to the physiological stage (either 1WPP or 2MPP) and then to the diet (samples from n-3 or control n-6 cows). The graphical heatmap representation of the analysis is shown in Figure 4A and the expression data of all genes are provided in Table 4. Four different clusters exhibiting a high threshold $(>0.7)$ were found. Cluster 1 was composed of 7 genes overexpressed at 1WPP compared with 2MPP (ADIPOR2, FOXO, LEP, PLIN2, PNPLA2, RARRES2, and RETN). Cluster 2 was composed of 11 genes overexpressed in n-3 compared with n- 6 AT samples at both stages (ADIPOQ, ADIPOR1, CD36, CHEMR23, DGAT1, FABP4, FFAR4, LIPE, PLIN1, $P P A R G$, and RBP4). Cluster 3 was composed of 11 genes overexpressed at $2 \mathrm{MPP}$ compared with $1 \mathrm{WPP}$ (APLN, CPT1A, ELOV1, FASN, GPR40, GPR43, $L P L, P A I, R O R 1, S C D 1$, and SREBP1). Cluster 4 was composed of 8 genes overexpressed in n- 6 compared with n-3 AT samples (APPL1, CPT2, GPR84, LEPR, NAMPT, NFkB, PPARD, and PTGS2). The genes that exhibited a dietary effect belonged mostly to clusters 2 and 4. Indeed, in cluster 2, 7 genes (ADIPOQ, FABP 4, FFAR4, LIPE, PLIN1, PPARG, and RBP4) had a significant diet effect $(P \leq 0.05$, Table 4$)$ and were overexpressed in the n-3 group, with $C D 36$ showing the same tendency $(P=0.09$, Table 4 , Figure $4 \mathrm{~B})$. The $L P L$ gene, belonging to cluster 3 , also tended to be overexpressed in the n-3 group $(P=0.09$, Table 4$)$.

For PPARG, it must be noted that the diet effect observed in the global analysis could be partly confounded with an effect of parity within year or diet, found in yr 1 or n-3 diet cows. For example, we found a trend for an overexpression in parity 1 cows compared with parity 2 cows $(P=0.083)$ in favor of $\mathrm{n}-3$ diet, as more parity 1 cows were in the n-3 diet group during yr 1 .

Interestingly, FABP 4 and $C D 36$ were expressed at a significantly greater level in n-3 compared with control n-6 AT samples at 1WPP (1.52-fold increase, $P=$ 0.004 , and 1.27 -fold increase, $P=0.043$, respectively); PLIN1 followed the same tendency (1.35-fold increase, $P=0.095$; Figure 4B). In contrast, gene expression in cluster 4 was lower in the n-3 group than in n- 6 group. A significant diet effect was observed for $N F \kappa B(P=$ 0.028 ) and the same tendency was observed for 3 other genes (CPT2, $P=0.09 ; L E P R, P=0.09$; and NAMPT, $P=0.06$; Figure $4 \mathrm{~B})$. The expression of $T L R 4$, not

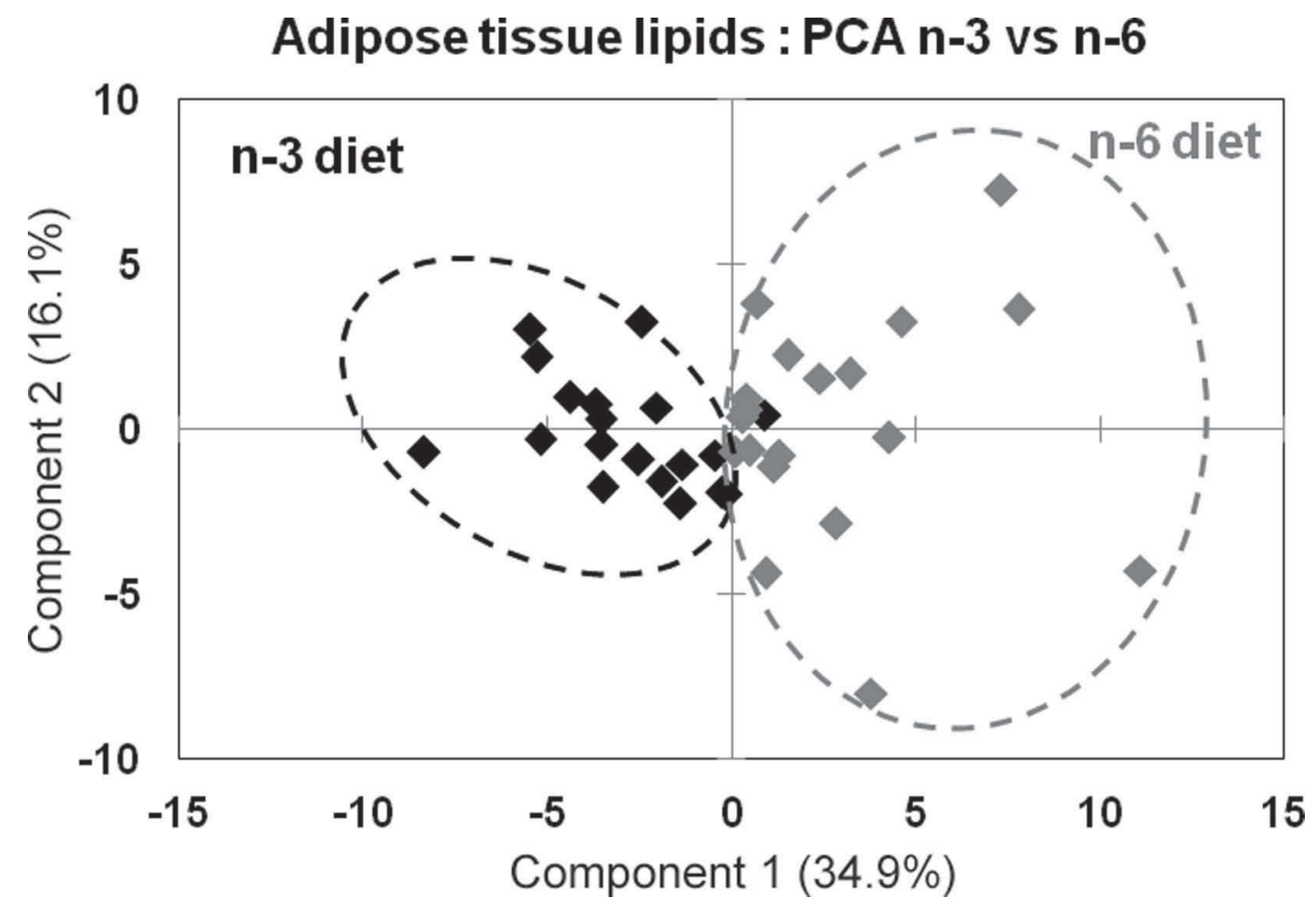

Figure 2. Effect of n-3 diet on dairy cow differential lipid peaks at 2 mo postpartum. Matrix-assisted laser desorption/ionization timeof-flight (MALDI-TOF) mass spectrometry analyses were performed after Folch extraction of subcutaneous adipose tissues collected at 2 mo postpartum after the $\mathrm{n}-3$ or $\mathrm{n}-6$ diet in both positive and negative modes $(\mathrm{n}=19$ for each diet). A principal component analysis (PCA) was performed on the 37 most differential peaks, 22 in the positive mode and 15 in the negative mode $(P<0.05$, fold change $>1.5$ or $<0.75)$. Results of 19 samples per diet are presented in this analysis. 
ELIS ET AL.

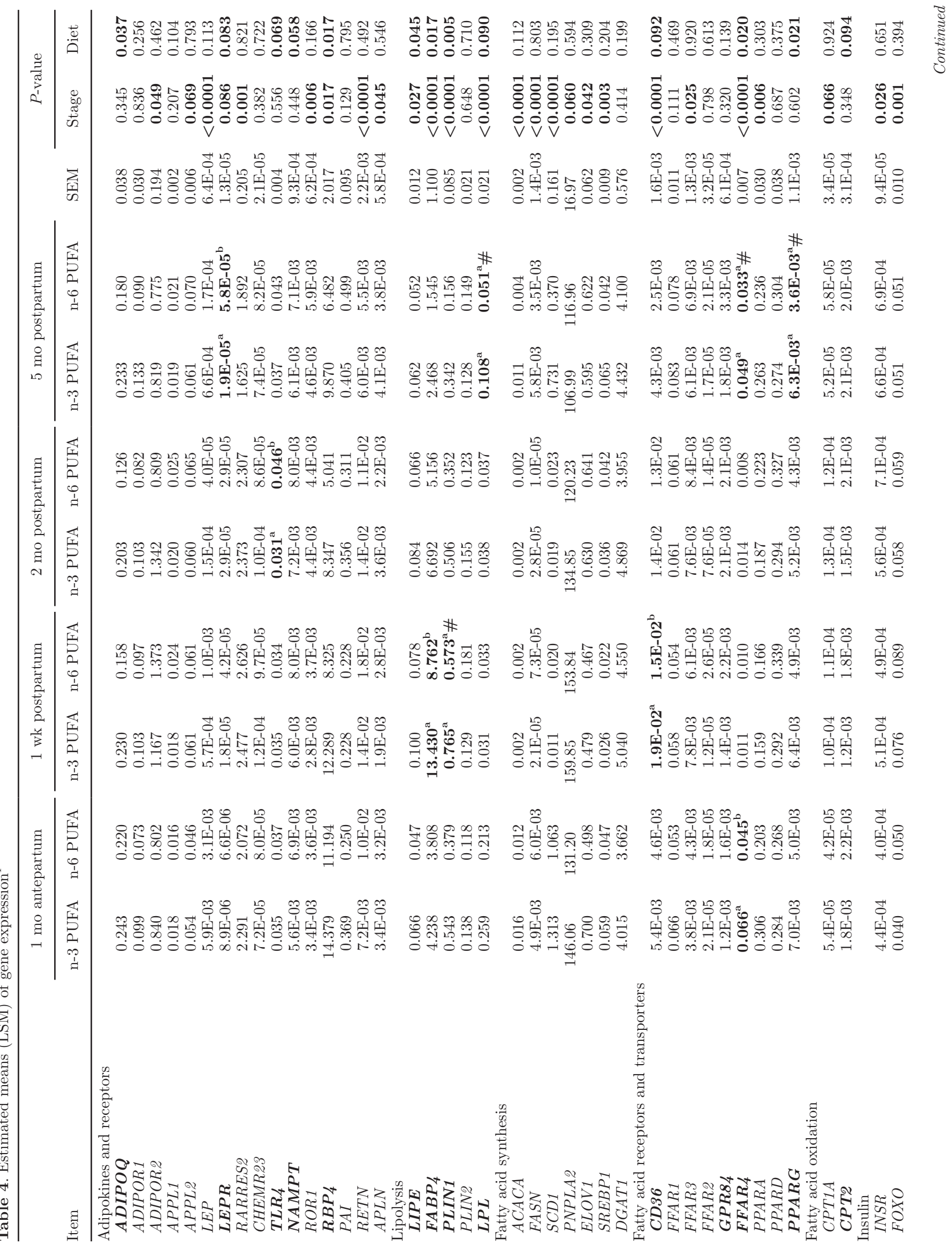


belonging to any of the clusters, also tended to be lower in the $\mathrm{n}-3$ group $(P=0.07)$.

For $N F \kappa B, L E P R$, and $T L R 4$, it must be noted that the diet effect observed in the global analysis could be partly confounded with an effect of parity within year or diet, found in yr 1 or n-3 diet cows. For example, we found a trend for a lower expression in parity 1 cows compared with parity 2 cows $(P=0.109, P=0.10$ and $P=0.065$ for $N F \kappa B, L E P R$ and TLR 4 respectively) in favor of the $\mathrm{n}-6$ diet, as more parity 1 cows were in the n-3 diet group during yr 1 .

\section{Correlations Between Gene Expression and Plasma EPA and DHA Concentrations}

Pearson correlations between the mRNA expression levels of the 44 studied genes were analyzed. Genes involved in similar functions showed significant correlations. For example, SCD1, ACACA, FASN, and $L P L$, genes contributing to lipid accumulation, had correlated expression $(\mathrm{r}>0.5, P<0.001)$, and therefore confirmed the clustering established according to stages, as they all belonged to cluster 1 (Figure 3A). Moreover, LIPE, $P L I N 1, F A B P 4$, and CD36, genes involved in lipolysis or fatty acid transport, also had correlated expression (r $>0.5, P<0.001$ ) and all belonged to cluster 3 (Figure $3 \mathrm{~A})$.

Pearson correlations between mRNA expression levels of the 44 studied genes and the sum of plasma EPA and DHA concentrations were also analyzed at 1WPP (Table 5). Among the genes studied, 15 showed significant positive correlations $(\mathrm{r} \geq 0.5, P<0.05)$ with plasma EPA and DHA concentrations (Figure 5): ACACA, ADIPOQ, DGAT1, FFAR4, GPR84, LIPE, LPL, NAMPT, PAI, PLIN1, PPARD, PPARG, RBP4, $S C D 1$, and TLR4. Thus, the expression of several fatty acid metabolism-related genes was correlated with plasma n-3 PUFA enrichment.

\section{Dietary Effect on AT Protein Expression}

To confirm the effects observed on mRNA expression, the expression of lipolytic proteins (FABP4, HSL, and PLIN1) was assessed by Western blotting (Figure 6). Protein FABP4 presented a significant 1.7-fold increase in n-3 AT compared with control n-6 samples $(P=$ 0.026 ). No significant difference in HSL expression was observed. Nevertheless, a significant 2.6-fold increase in HSL phosphorylation (ratio of phosphorylated HSL to total HSL) in n-3 AT compared with control n-6 samples was measured $(P=0.008)$. The PLIN1 presented a significant 2.1-fold increase in n-3 AT compared with control n-6 samples $(P=0.009)$ and phosphorylated PLIN1 followed the same tendency $(P=0.060)$. 


\section{DISCUSSION}

In this study, we compared lipid profiles and gene expression in adipose tissues of cows supplemented either with n-3 or n-6 PUFA for 2 mo after calving. Our data suggest that an n-3 PUFA diet could enhance lipolysis in AT.

\section{Efficiency of the Diet: Plasma and AT Fatty Acid Composition Enriched in n-3 PUFA}

As previously described (Elis et al., 2016), the dose and form of n-3 supplementation (rumen protected fish oil) led to a significant increase in plasma EPA and DHA concentrations in cows from an n-3 diet group without affecting zootechnical parameters (BW, MY, DMI, EB, and AT thickness). This expected increase was consistent with lipid profiles in AT reported in the present study: n-3 AT samples showed an increased intensity of ions corresponding to glycerophospholipids, partly composed of either EPA (20:5 n-3) or DHA (22:6 $\mathrm{n}-3)$, according to the annotations $(774.5 \mathrm{~m} / \mathrm{z}$ for glycerophosphoethanolamine and 802.5 and $852.5 \mathrm{~m} / \mathrm{z}$ for diacylglycerophosphocholine), which is consistent with the composition of the fish oil used (18\% EPA and $12 \%$ DHA). The n-3 dietary supplementation was previously
A.

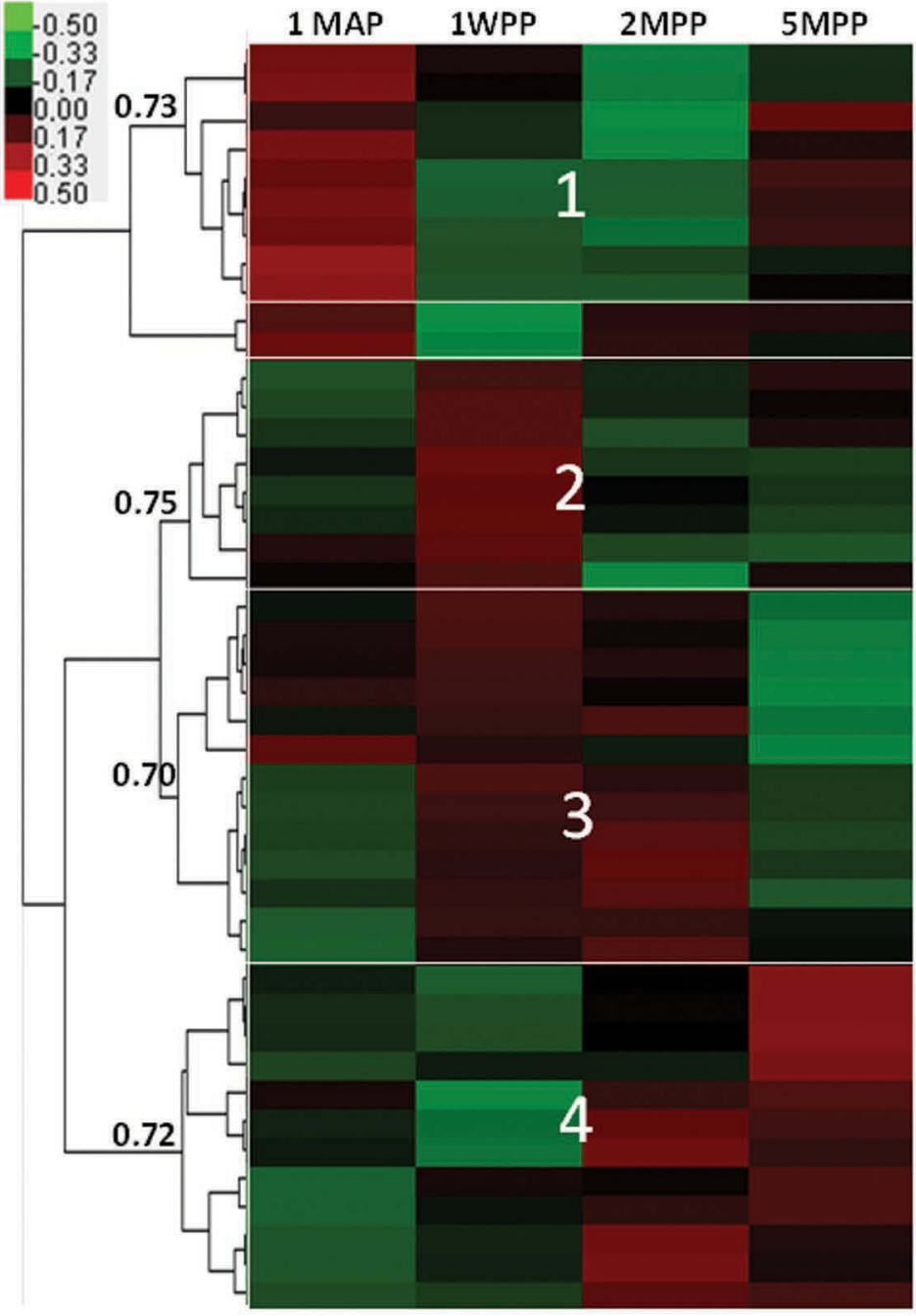

LEP

RBP4

$A P L N$

ADIPOQ

FASN

$S C D 1$

FFAR4

$L P L$

ACACA

SREBP1

CPT2

ADIPOR1

DGAT1

PLIN2

ADIPOR2

CHEMR 23

FOXO

PNPLA2

FFAR2

RARRES 2

RETN

FABP 4

PLIN1

CD36

PPARG

LIPE

PTGS2

NAMPT

CPT1A

PTEN

PPARD

APPL 1

PAI

ROR1

FFAR 1

GPR84

PPARA

ELOV1

TLR4

LEPR

APPL 2

FFAR3

$N F \times B$

INSR
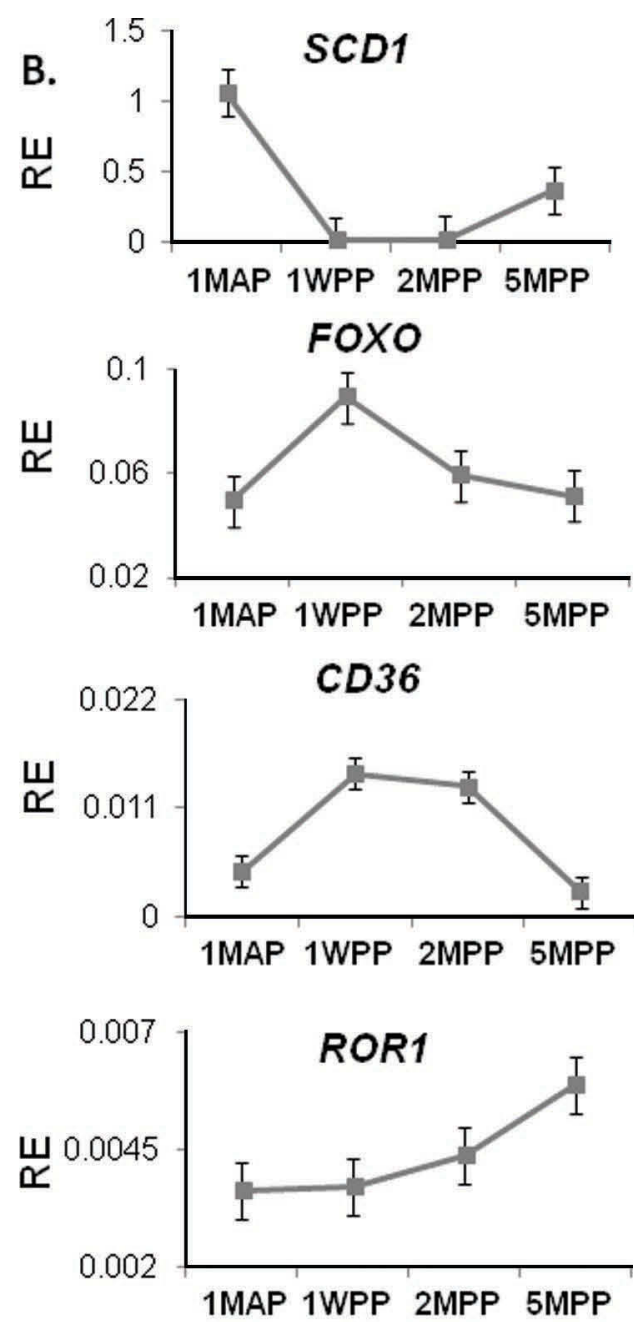

Control diet

Figure 3. Supervised hierarchical clustering of genes in adipose tissue according to kinetic properties. Real time reverse transcription-PCR analysis was performed on control samples (n-6) taken at 4 different stages, 1 mo antepartum (1MAP), 1 wk postpartum (1WPP), and 2 (2MPP) and 5 mo postpartum (5MPP) with 23 biological replicates. Relative expression is measured relative to the geometric mean of the expression of 3 housekeeping genes (PPIA, RPS9, and RPL19) by real time reverse transcription-PCR. (A) Supervised hierarchical clustering of genes was performed using Cluster 3.0 software. Four clusters stand out, and node correlation thresholds are indicated for each cluster. (B) One example of each pattern is presented as LSM \pm SEM. For these 4 examples, only the control n- 6 diet is represented (gray line). RE $=$ relative expression. 
reported to increase n-3 fatty acid composition in cow AT (Zachut et al., 2010; Corazzin et al., 2013). However, AT from n-6 cows (toasted soy seed supplementation) showed a potentially increased intensity of ions corresponding to triacylglycerols (895.8, 907.8, and 909.8 $\mathrm{m} / \mathrm{z}$ ) with increased 18:2 fatty acids. This is consistent with the composition of soy oil, enriched in 18:2 n- 6 (around $50 \%$ of the total fatty acids of soy are 18:2 and $20 \%$ are 18:1; Robinson et al., 2002). Adipose tissue is known to have an important role in the effect of PUFA (Kopecky et al., 2009) due to its storage capacity for triacylglycerols (Flachs et al., 2009), which was consistent with the modifications of lipid profiles observed after n-3 or n-6 diets. Despite these modifications, the difference between n-3 and n-6 AT lipid composition was moderate.

\section{Effect of n-3 Diet on Gene Expression in AT}

Only 8 genes differed in AT mRNA levels between n-3 and n-6 groups (significant diet effect). This was expected because the production and metabolic phenotype of cows receiving either n-3 or n-6 diets revealed no modifications in BW, milk production, DMI, EB, fat thickness, urea, glucose, and plasma fatty acids (Elis et al., 2016). Nevertheless, the diet significantly affected the expression of lipolytic genes (LIPE, PLIN1, CD36, and FABP4), which were overexpressed in n-3 AT

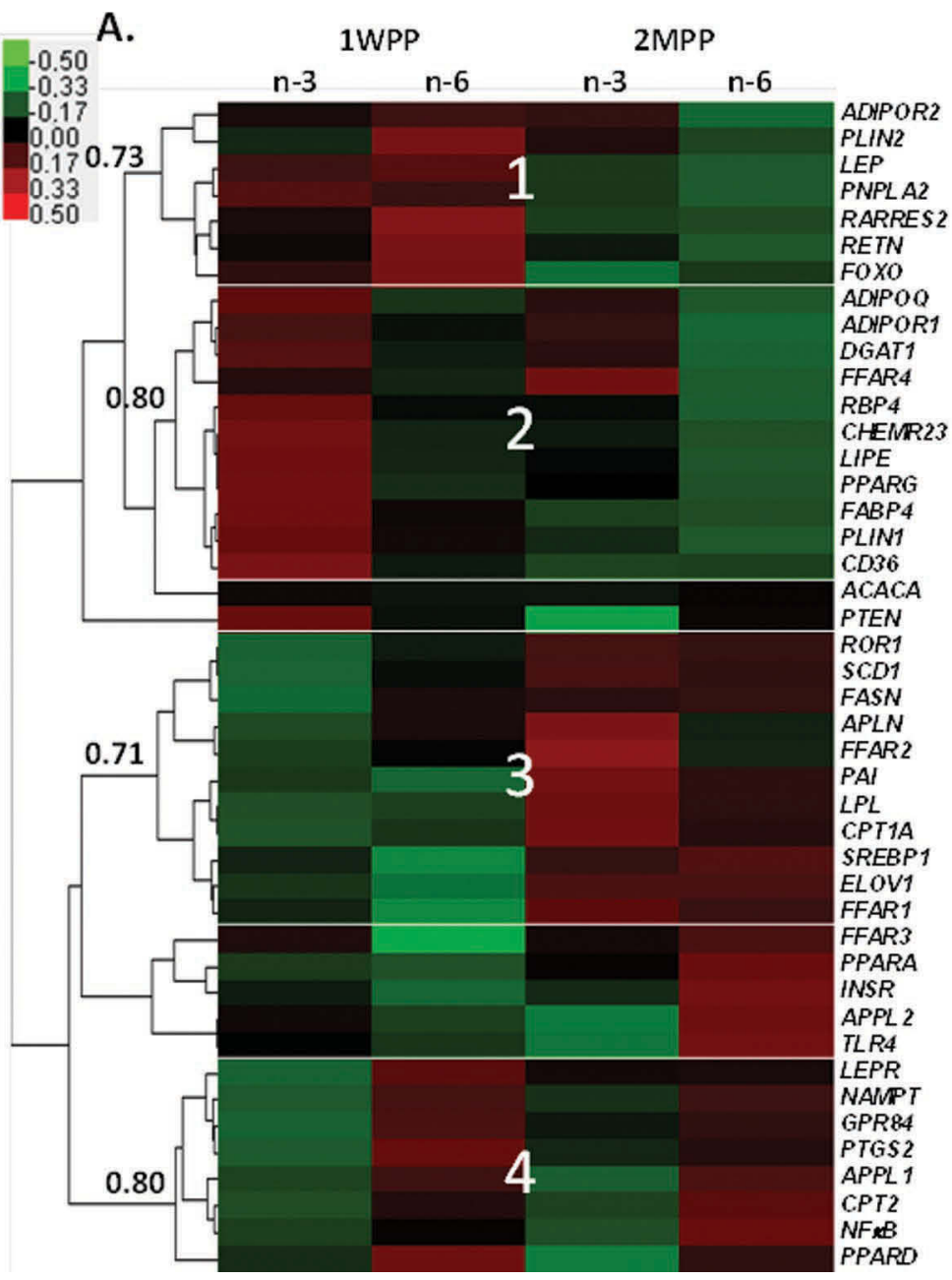

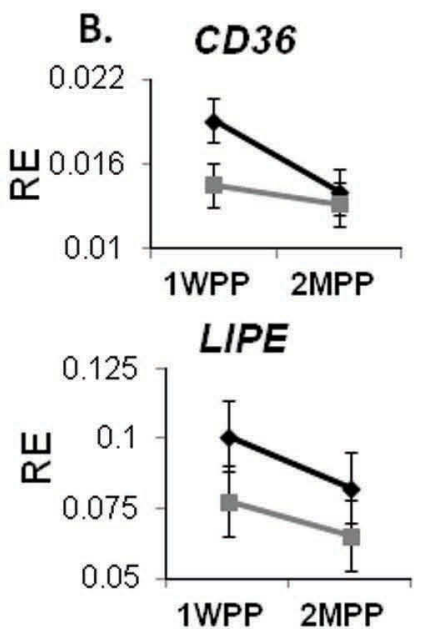
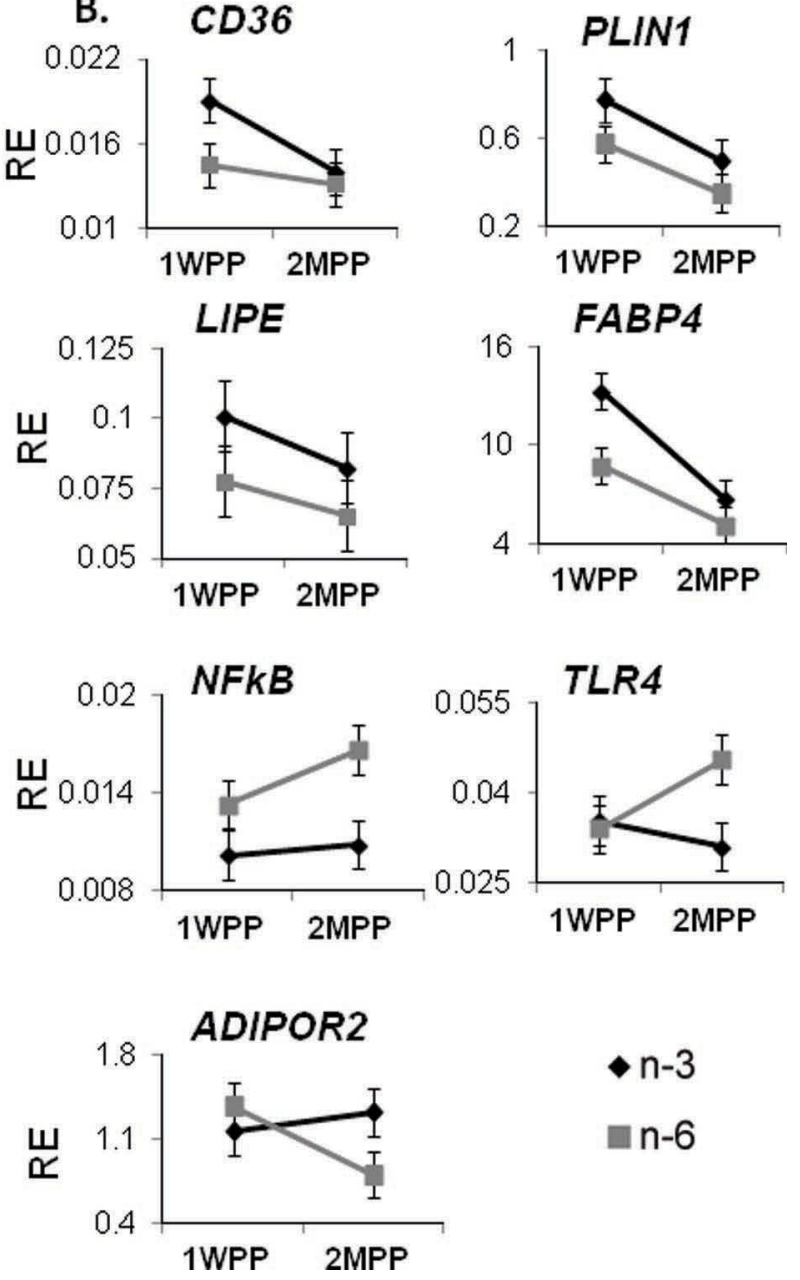

$\bullet \mathrm{n}-3$

n-6

Figure 4. Supervised hierarchical clustering of genes in adipose tissue according to diet. Real time reverse transcription-PCR analysis was performed on n-3 and n-6 samples (23 biological replicates for each diet) taken at 2 different stages during the diet, 1 wk postpartum (1WPP) and 2 mo postpartum (2MPP). Relative expression is measured relative to the geometric mean of the expression of 3 housekeeping genes $(P P I A$, RPS9, and RPL19) by real time reverse transcription-PCR. (A) Supervised hierarchical clustering of genes was performed using Cluster 3.0 software (Stanford University, Stanford, CA). Two clusters stand out (clusters 2 and 4), node correlation thresholds are indicated for each cluster. (B) Examples of genes exhibiting a diet effect are presented as LSM \pm SEM: n-3 diet (black line) and n-6 diet (gray line). RE $=$ relative expression. 
Table 5. Pearson correlations between gene expression levels and the sum of plasma eicosapentaenoic acid (EPA) and docosahexaenoic acid (DHA) levels, at 1 wk postpartum ${ }^{1}$

Diet stage: 1 wk postpartum, both diets

\begin{tabular}{|c|c|c|}
\hline Gene & $\mathrm{r}$ & $P$-value \\
\hline$A C A C A$ & 0.63 & 0.001 \\
\hline$A D I P O Q$ & 0.63 & 0.001 \\
\hline ADIPOR 1 & 0.49 & 0.006 \\
\hline ADIPOR2 & 0.12 & 0.519 \\
\hline$A P L N$ & 0.41 & 0.032 \\
\hline$A P P L 1$ & 0.41 & 0.026 \\
\hline APPL2 & 0.23 & 0.222 \\
\hline CD36 & 0.49 & 0.007 \\
\hline CHEMR23 & 0.45 & 0.015 \\
\hline CPT1A & 0.34 & 0.074 \\
\hline СРТ2 & 0.37 & 0.048 \\
\hline$D G A T 1$ & 0.56 & 0.002 \\
\hline ELOV1 & 0.19 & 0.330 \\
\hline$F A B P 4$ & 0.49 & 0.006 \\
\hline$F A S N^{\top}$ & 0.28 & 0.141 \\
\hline FFAR1 & -0.12 & 0.551 \\
\hline FFAR2 & 0.01 & 0.943 \\
\hline FFAR3 & -0.05 & 0.788 \\
\hline FFAR4 & 0.64 & 0.001 \\
\hline FOXO & -0.44 & 0.016 \\
\hline GPR84 & 0.59 & 0.001 \\
\hline$I N S R$ & 0.14 & 0.459 \\
\hline$L E P$ & 0.33 & 0.081 \\
\hline$L E P R$ & -0.18 & 0.361 \\
\hline$L I P E$ & 0.63 & 0.001 \\
\hline$L P L$ & 0.59 & 0.001 \\
\hline$N A M P T$ & 0.53 & 0.003 \\
\hline$N F k B$ & 0.49 & 0.006 \\
\hline$P A I$ & 0.59 & 0.001 \\
\hline PLIN1 & 0.51 & 0.005 \\
\hline PLIN2 & 0.32 & 0.088 \\
\hline PNPLA2 & -0.44 & 0.023 \\
\hline PPARA & 0.48 & 0.011 \\
\hline$P P A R D$ & 0.52 & 0.004 \\
\hline$P P A R G$ & 0.59 & 0.001 \\
\hline PTEN & -0.46 & 0.011 \\
\hline PTGS2 & -0.14 & 0.479 \\
\hline RARRESQ & -0.26 & 0.171 \\
\hline$R B P 4$ & 0.69 & $<0.0001$ \\
\hline RETN & 0.32 & 0.092 \\
\hline ROR 1 & 0.21 & 0.277 \\
\hline$S C D 1$ & 0.55 & 0.002 \\
\hline$S R E B P 1$ & 0.24 & 0.214 \\
\hline$T L R_{4}$ & 0.64 & 0.001 \\
\hline
\end{tabular}

${ }^{1}$ Text in bold indicates a significant correlation $(P \leq 0.05)$ with $|\mathrm{r}|$ $\geq 0.5$.

samples during the diet; LIPE and PLIN1 expression was also positively correlated with plasma EPA and DHA level at 1WPP, and PLIN1 protein expression and the phosphorylation of HSL and PLIN1 was also increased in n-3 AT samples at 1WPP, suggesting increased lipolytic activity in AT. In contrast, lipogenic genes did not differ between groups. Lipolytic genes are involved in energy mobilization from triglyceride storage and thus in providing fatty acids to other tissues. This is consistent with the decrease in triacylglycerols observed in the n-3 AT lipid profiles. Such a decrease in triacylglycerols has previously been reported in mice with no plasma fatty acid increase after EPA or DHA supplementation (Ruzickova et al., 2004). Moreover, an increase in lipolysis, partly through LIPE expression following an n-3 diet, has already been reported in fish (Liu et al., 2014) as well as in mice and humans (Tai and Ding, 2010). The n-3 diets have previously been associated with the suppression of AT lipogenesis in humans and mice (Tai and Ding, 2010; Masoodi et al., 2015), which was not observed in the present study. However, in the current study, lipogenic genes were naturally suppressed during the diet period when early lactation, and therefore body reserve mobilization, occurs. Therefore, no additional inhibition of lipogenic genes during this period was expected. It would be interesting to further investigate the mechanisms of action by addressing the hypothesis that protein kinase A pathways might be involved in the n- 3 PUFA effects observed on AT. Indeed, DHA and EPA have already been reported to exert effects through protein kinase A pathway (Tai et al., 2009; Fournier et al., 2016), which leads to HSL phosphorylation (Ruggles et al., 2013). Phosphorylation of HSL increases lipolytic activity, thus decreasing triacyglycerol reserves and consequently increasing fatty acids.

Diet had a significant effect on the expression of 3 genes (FFAR 4, PPARG, and $N F \kappa B$ ) potentially involved in n-3 PUFA action mechanisms; the expression of both FFAR4 and PPARG is also positively correlated with plasma EPA and DHA levels at $1 \mathrm{WPP}$. The DHA is able to bind transcription factors such as peroxisome proliferator-activated receptor $\gamma$ and $\alpha$ (PPARG and PPARA); PPARG is a master regulator of adipogenesis (Shao et al., 2016) and is mainly involved in lipid catabolism (Masoodi et al., 2015). Peroxisome proliferator-activated receptor improves insulin sensitivity (Calder, 2012; Lefterova et al., 2014); therefore, an n-3 PUFA diet might decrease insulin resistance due to the intense lipolysis occurring during early lactation (Sinclair, 2010). Moreover, n-3 PUFA can also bind to surface or intracellular fatty acid receptors or sensors, such as $\mathrm{G}$ protein-coupled surface receptors (FFAR4), thus activating their signaling pathways (Calder, 2012). Moreover, Gotoh et al. (2007) suggested that FFAR4 could be a regulator of lipolysis.

The n-3 PUFA DHA may have several additional functions in bovine AT cells, notably adipocytes. Docosahexaenoic acid could affect these cells via changes in the composition of cell membrane phospholipids. Indeed, fatty acids in cell membranes can affect protein function by modifying membrane fluidity and lipid raft formation, as shown in human mononuclear cells 

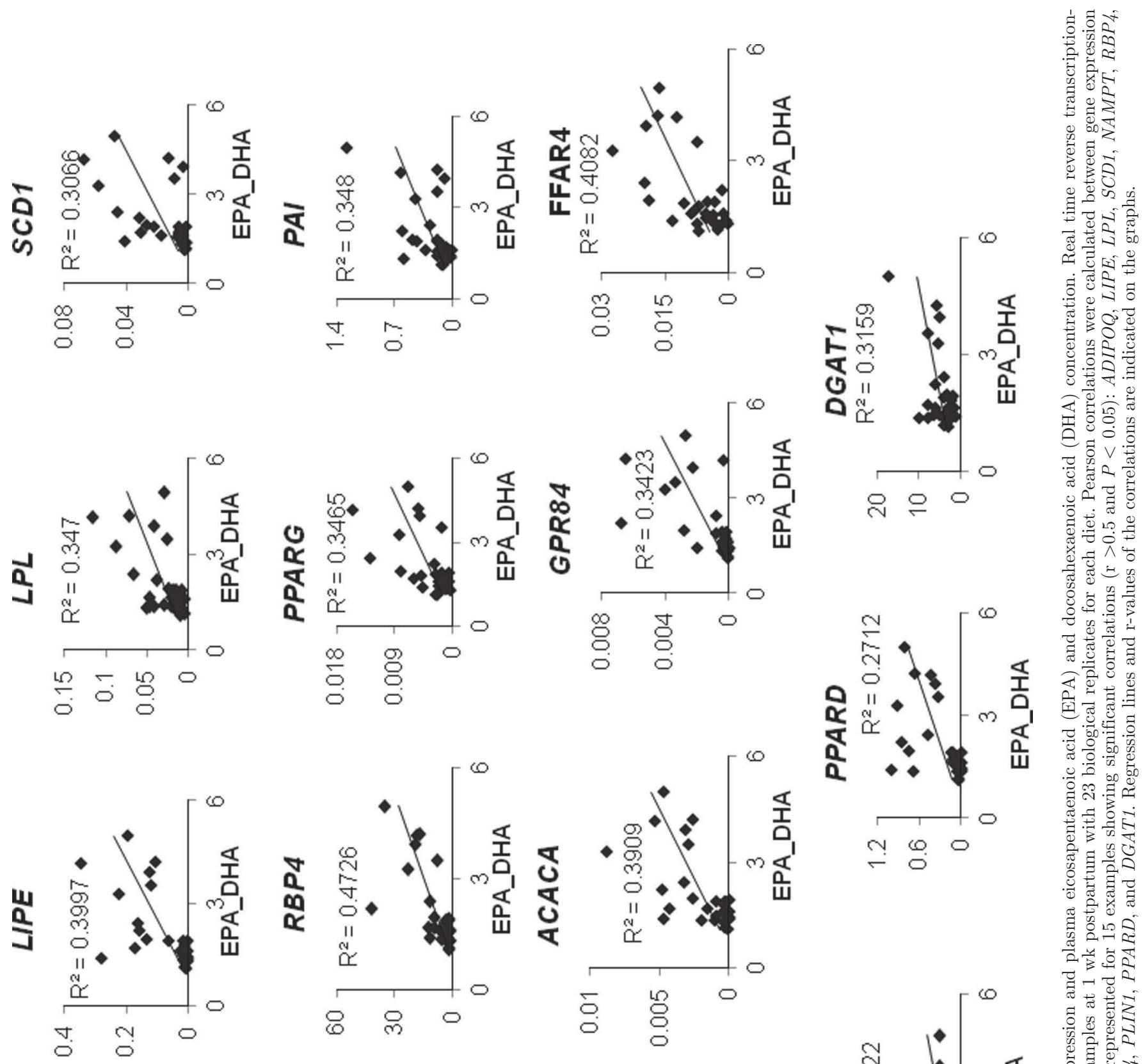

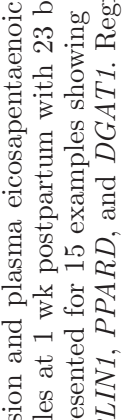

页

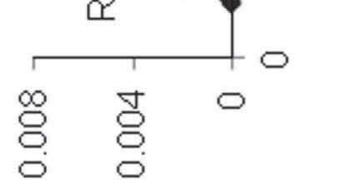
$\stackrel{\infty}{\circ} \stackrel{\circ}{8}$

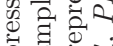

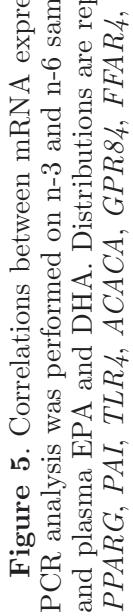


(Calder, 2011). Lipid rafts appear to act as signaling platforms, as many proteins involved in signal transduction are mostly found in lipid rafts (Pike, 2003); therefore, long-chain n-3 PUFA could influence raft formation and function (Shaikh et al., 2009).

The n-3 diet affected the expression of several adipokines or their receptor genes. The effect of diet on the expression of 2 adipokines, adiponectin $(A D I P O Q)$ and $R B P 4$, was significant, and visfatin (NAMPT) and leptin receptor ( $L E P R$ ) gene expression showed the same tendency. Moreover, 4 adipokine genes had a positively correlated expression with plasma EPA and DHA concentrations (ADIPOQ, NAMPT, PAI, and $R B P 4)$. Both EPA and DHA induced an increase in adiponectin secretion in mouse and humans (Itoh et al., 2007; Kopecky et al., 2009). Moreover, ADIPOR1 was

A.

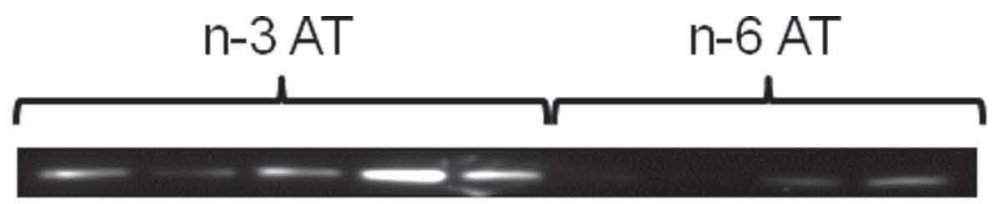

FABP4 - $14 \mathrm{kDa}$

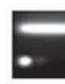

HSL - 81kDa

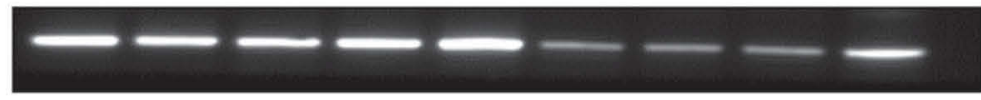

$\mathrm{pHSL}-81 \mathrm{kDa}$

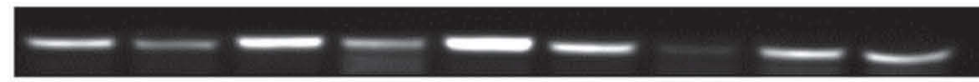

PLIN1 - $57 \mathrm{kDa}$

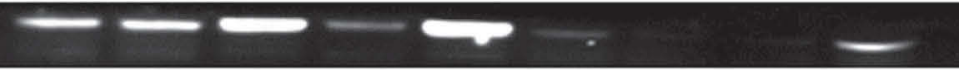

pPLIN1 - $57 \mathrm{kDa}$

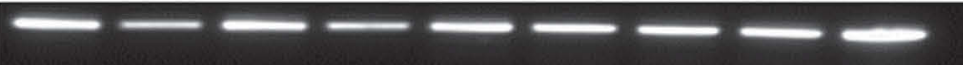

\section{VCL - $116 \mathrm{kDa}$}

B.

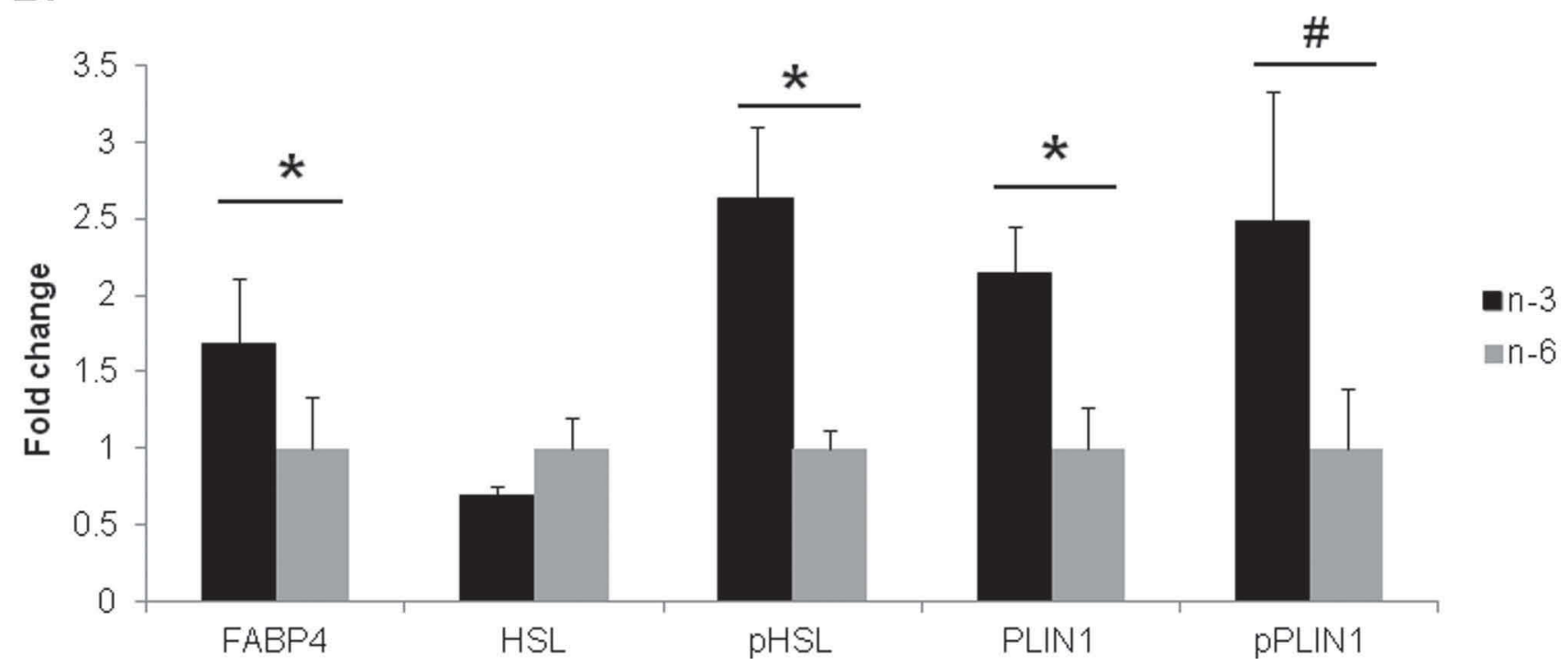

Figure 6. Effect of n-3 diet on dairy cow protein expression in adipose tissue (AT) at 1 wk postpartum. Western blotting analysis was performed on n-3 and control n-6 samples at 1 wk postpartum with 19 and 15 biological replicates, respectively. Expression of fatty acid binding protein 4 (FABP4), hormone sensitive lipase (HSL), and perilipine 1 (PLIN1) protein was measured relative to the expression of the reporter protein vinculin (VCL). Phosphorylation of HSL (pHSL) and PLIN1 (pPLIN1) is presented as the ratio of expression of the phosphorylated protein to the expression of the total protein, HSL, and PLIN1, respectively. (A) Examples of the Western blotting images are presented, showing the expression of all the proteins measured from the 9 same animals. (B) Results are presented as means \pm SEM; * indicates significant difference $(P<0.05)$ and \# indicates tendency $(P<0.10)$. 
a regulatory switch of DHA uptake in mouse photoreceptors (Rice et al., 2015); nevertheless, adipokines are regulated post-translationally (Giesy et al., 2012). It is thus important to investigate whether the changes in adipokine mRNA expression are also evidenced at the protein level before suggesting a potential effect of n-3 PUFA diet through secretory functions of the adipose tissue.

\section{Kinetics of Gene Expression in AT During Lactation}

Gene expression in AT varied dynamically throughout lactation, as expected. This was similar in n-3 and n-6 diet groups and no significant interaction between stage and diet effect was observed. During the period of body reserve reconstitution (1MAP and 5MPP), we found that lipogenic enzymes (ACACA, FASN, and $S C D 1)$ were greatly overexpressed in comparison to a large set of analyzed lipid metabolism-related genes. These results are consistent with previously published data and confirm that transcription is the main regulatory mechanism of AT lipogenesis (Elis et al., 2013; Khan et al., 2013). In contrast, lipolytic genes and genes involved in fatty acid transport (CD36, FABP4, $L I P E$, and PLIN1) were overexpressed during the lipid mobilization period (between 1WPP and 2MPP). The increase in LIPE and PLIN1 AT expression level during early lactation compared with prepartum stages is consistent with previously reported data in cows (Sumner and McNamara, 2007; Sumner-Thomson et al., 2011; Elis et al., 2013). Nevertheless, this increase was not as great in magnitude as the increase of lipogenic enzymes, which is consistent with the hypothesis that the main regulation of lipolytic genes is not transcriptional, as is the case for lipogenic genes, but post-translational (Khan et al., 2013).

Different adipokine genes exhibited opposite patterns of dynamic variation in gene expression to one another. We found that chemerin (RARRES2) and resistin $(R E T N)$ genes were overexpressed in AT during the mobilization stage and ADIPOR2 was increased after calving, thus corroborating previously published data (Elis et al., 2013). Indeed, an increase in RETN expression during early lactation may promote lipid mobilization (Reverchon et al., 2014). However, other adipokine genes, such as leptin $(L E P)$, retinol-binding protein $(R B P 4)$, and apelin $(A P L N)$, were overexpressed during the stage of body reserve reconstitution and are consistent with LEP expression patterns reported in previous studies (Lemor et al., 2009; Elis et al., 2013). In rat mammary glands, APLN was overexpressed during late pregnancy compared with early lactation stages (Habata et al., 1999), which is consistent with overexpression at $1 \mathrm{MAP}$, as reported in the pres- ent study. Moreover, the fatty acid receptor FFAR3 (alias GPR 41) is involved in monitoring energy storage (Covington et al., 2006) and related to leptin synthesis (Xiong et al., 2004). Increasing FFAR3 expression in AT during postpartum stages may be a long-term response to the negative energy balance when insulin and leptin are low (Lemor et al., 2009).

This study provided interesting insights on the potential effects of n-3 PUFA on adipose tissue. It is, however, important to keep in mind that this study was performed on subcutaneous AT samples collected from the dewlap. It would be complementary to investigate if the same effects on lipolysis could be observed with samples collected from other adipose sites, subcutaneous fat, and especially abdominal fat. Concerning the lipid profiling approach, it is important to confirm our results (relying on lipid annotations) by the precise identification of the differential lipids, through the fragmentation of each species.

\section{CONCLUSIONS}

In this work, we have studied the effect of n-3 or n-6 PUFA enriched diets on gene expression and lipid profiles in AT in dairy cows. The most interesting finding was that gene expression (lipolytic genes), protein expression (lipolytic activity) and lipid profiles suggested that lipolysis could be enhanced in AT of cows that received the $\mathrm{n}-3$ diet, potentially providing a more favorable energy supply.

\section{ACKNOWLEDGMENTS}

We thank the technical staff of the research (PRC) and experimental (UEPAO) units in INRA Val de Loire Centre (Jean-Luc Touzé, Christelle Ramé, Mickael Dupont, Mickael Delanoue, Christophe Mouaze, Ludovic Métivier, and Damien Capo). The INRA, Apis-Gene (Paris, France), and the Regional Council (Région Centre-Val de Loire, France) financially supported this work. The MALDI-TOF/TOF mass spectrometer was financed by the Région Centre-Val de Loire and by INRA.

\section{REFERENCES}

Calder, P. C. 2011. Fatty acids and inflammation: The cutting edge between food and pharma. Eur. J. Pharmacol. 668(Suppl. 1):S50S58.

Calder, P. C. 2012. Mechanisms of action of (n-3) fatty acids. J. Nutr. 142:592S-599S

Cha, S. H., A. Fukushima, K. Sakuma, and Y. Kagawa. 2001. Chronic docosahexaenoic acid intake enhances expression of the gene for uncoupling protein 3 and affects pleiotropic mRNA levels in skeletal muscle of aged C57BL/6NJcl mice. J. Nutr. 131:2636-2642. 
Corazzin, M., S. Bovolenta, E. Saccà, G. Bianchi, and E. Piasentier. 2013. Effect of linseed addition on the expression of some lipid metabolism genes in the adipose tissue of young Italian Simmental and Holstein bulls. J. Anim. Sci. 91:405-412.

Covington, D. K., C. A. Briscoe, A. J. Brown, and C. K. Jayawickreme. 2006. The G-protein-coupled receptor 40 family (GPR40GPR43) and its role in nutrient sensing. Biochem. Soc. Trans. 34:770-773.

Eisen, M. B., P. T. Spellman, P. O. Brown, and D. Botstein. 1998. Cluster analysis and display of genome-wide expression patterns. Proc. Natl. Acad. Sci. USA 95:14863-14868.

Elis, S., S. Coyral-Castel, S. Freret, J. Cognié, A. Desmarchais, A. Fatet, C. Rame, E. Briant, V. Maillard, and J. Dupont. 2013. Expression of adipokine and lipid metabolism genes in adipose tissue of dairy cows differing in a female fertility quantitative trait locus. J. Dairy Sci. 96:7591-7602.

Elis, S., S. Freret, A. Desmarchais, V. Maillard, J. Cognié, E. Briant, J.-L. Touzé, M. Dupont, P. Faverdin, V. Chajès, S. Uzbekova, P. Monget, and J. Dupont. 2016. Effect of a long chain n-3 PUFAenriched diet on production and reproduction variables in Holstein dairy cows. Anim. Reprod. Sci. 164:121-132.

Fasshauer, M., and M. Bluher. 2015. Adipokines in health and disease. Trends Pharmacol. Sci. 36:461-470.

Flachs, P., M. Rossmeisl, M. Bryhn, and J. Kopecky. 2009. Cellular and molecular effects of n-3 polyunsaturated fatty acids on adipose tissue biology and metabolism. Clin. Sci. 116:1-16.

Folch, J., M. Lees, and G. H. Sloane Stanley. 1957. A simple method for the isolation and purification of total lipids from animal tissues. J. Biol. Chem. 226:497-509.

Fournier, N., S. Tardivel, J. F. Benoist, B. Vedie, D. Rousseau-Ralliard, M. Nowak, F. Allaoui, and J. L. Paul. 2016. Eicosapentaenoic acid membrane incorporation impairs ABCA1-dependent cholesterol efflux via a protein kinase A signaling pathway in primary human macrophages. Biochim. Biophys. Acta 1861:331-341.

Galamb, E., V. Faigl, M. Keresztes, Z. Csillik, A. Troscher, P. Elek, M. Kulcsar, G. Huszenicza, H. Febel, and F. Husveth. 2016. Effect of pre- and post-partum supplementation with lipid-encapsulated conjugated linoleic acid on milk yield and metabolic status in multiparous high-producing dairy cows. J. Anim. Physiol. Anim. Nutr. (Berl.). http://dx.doi.org/10.1111/jpn.12544.

Giesy, S. L., B. Yoon, W. B. Currie, J. W. Kim, and Y. R. Boisclair. 2012. Adiponectin deficit during the precarious glucose economy of early lactation in dairy cows. Endocrinology 153:5834-5844.

Gotoh, C., Y. H. Hong, T. Iga, D. Hishikawa, Y. Suzuki, S. H. Song, K. C. Choi, T. Adachi, A. Hirasawa, G. Tsujimoto, S. Sasaki, and S. G. Roh. 2007. The regulation of adipogenesis through GPR120. Biochem. Biophys. Res. Commun. 354:591-597.

Habata, Y., R. Fujii, M. Hosoya, S. Fukusumi, Y. Kawamata, S. Hinuma, C. Kitada, N. Nishizawa, S. Murosaki, T. Kurokawa, H. Onda, K. Tatemoto, and M. Fujino. 1999. Apelin, the natural ligand of the orphan receptor APJ, is abundantly secreted in the colostrum. Biochim. Biophys. Acta 1452:25-35.

Hiller, B., A. Herdmann, and K. Nuernberg. 2011. Dietary n-3 fatty acids significantly suppress lipogenesis in bovine muscle and adipose tissue: A functional genomics approach. Lipids 46:557-567.

Itoh, M., T. Suganami, N. Satoh, K. Tanimoto-Koyama, X. Yuan, M. Tanaka, H. Kawano, T. Yano, S. Aoe, M. Takeya, A. Shimatsu, H. Kuzuya, Y. Kamei, and Y. Ogawa. 2007. Increased adiponectin secretion by highly purified eicosapentaenoic acid in rodent models of obesity and human obese subjects. Arterioscler. Thromb. Vasc. Biol. 27:1918-1925.

Khan, M. J., A. Hosseini, S. Burrell, S. M. Rocco, J. P. McNamara, and J. J. Loor. 2013. Change in subcutaneous adipose tissue metabolism and gene network expression during the transition period in dairy cows, including differences due to sire genetic merit. J. Dairy Sci. 96:2171-2182.

Kopecky, J., M. Rossmeisl, P. Flachs, O. Kuda, P. Brauner, Z. Jilkova, B. Stankova, E. Tvrzicka, and M. Bryhn. 2009. n-3 PUFA: Bioavailability and modulation of adipose tissue function. Proc. Nutr. Soc. 68:361-369.
Lefterova, M. I., A. K. Haakonsson, M. A. Lazar, and S. Mandrup. 2014. PPARgamma and the global map of adipogenesis and beyond. Trends Endocrinol. Metab. 25:293-302.

Lemor, A., A. Hosseini, H. Sauerwein, and M. Mielenz. 2009. Transition period-related changes in the abundance of the mRNAs of adiponectin and its receptors, of visfatin, and of fatty acid binding receptors in adipose tissue of high-yielding dairy cows. Domest. Anim. Endocrinol. 37:37-44.

Liu, P., C. Li, J. Huang, and H. Ji. 2014. Regulation of adipocytes lipolysis by n-3 HUFA in grass carp (Ctenopharyngodon idellus) in vitro and in vivo. Fish Physiol. Biochem. 40:1447-1460.

Masoodi, M., O. Kuda, M. Rossmeisl, P. Flachs, and J. Kopecky. 2015. Lipid signaling in adipose tissue: Connecting inflammation \& metabolism. Biochim. Biophys. Acta 1851:503-518.

McNamara, J. P., and F. Valdez. 2005. Adipose tissue metabolism and production responses to calcium propionate and chromium propionate. J. Dairy Sci. 88:2498-2507.

McNamara, S., F. P. O'Mara, M. Rath, and J. J. Murphy. 2003. Effects of different transition diets on dry matter intake, milk production, and milk composition in dairy cows. J. Dairy Sci. 86:2397-2408.

Patton, J., D. A. Kenny, S. McNamara, J. F. Mee, F. P. O'Mara, M. G. Diskin, and J. J. Murphy. 2007. Relationships among milk production, energy balance, plasma analytes, and reproduction in Holstein-Friesian cows. J. Dairy Sci. 90:649-658.

Pike, L. J. 2003. Lipid rafts: Bringing order to chaos. J. Lipid Res. 44:655-667.

Plourde, M., and S. C. Cunnane. 2007. Extremely limited synthesis of long chain polyunsaturates in adults: Implications for their dietary essentiality and use as supplements. Appl. Physiol. Nutr. Metab. $32: 619-634$

Prokesch, A., H. Hackl, R. Hakim-Weber, S. R. Bornstein, and Z. Trajanoski. 2009. Novel insights into adipogenesis from omics data. Curr. Med. Chem. 16:2952-2964.

R Core Team. 2015. R: A language and environment for statistical computing. R-project, Vienna, Austria.

Reverchon, M., C. Rame, J. Cognie, E. Briant, S. Elis, D. Guillaume, and J. Dupont. 2014. Resistin in dairy cows: Plasma concentrations during early lactation, expression and potential role in adipose tissue. PLoS ONE 9:e93198.

Rice, D. S., J. M. Calandria, W. C. Gordon, B. Jun, Y. Zhou, C. M. Gelfman, S. Li, M. Jin, E. J. Knott, B. Chang, A. Abuin, T. Issa, D. Potter, K. A. Platt, and N. G. Bazan. 2015. Adiponectin receptor 1 conserves docosahexaenoic acid and promotes photoreceptor cell survival. Nat. Commun. 6:6628.

Robinson, R. S., P. G. Pushpakumara, Z. Cheng, A. R. Peters, D. R. Abayasekara, and D. C. Wathes. 2002. Effects of dietary polyunsaturated fatty acids on ovarian and uterine function in lactating dairy cows. Reproduction 124:119-131.

Rocco, S. M., and J. P. McNamara. 2013. Regulation of bovine adipose tissue metabolism during lactation. 7. Metabolism and gene expression as a function of genetic merit and dietary energy intake. J. Dairy Sci. 96:3108-3119.

Rozen, S., and H. J. Skaletsky. 2000. Primer3 on the WWW for general users and for biologist programmers. Methods Mol. Biol. 132:365-386.

Ruggles, K. V., A. Turkish, and S. L. Sturley. 2013. Making, baking, and breaking: The synthesis, storage, and hydrolysis of neutral lipids. Annu. Rev. Nutr. 33:413-451.

Ruzickova, J., M. Rossmeisl, T. Prazak, P. Flachs, J. Sponarova, M. Veck, E. Tvrzicka, M. Bryhn, and J. Kopecky. 2004. Omega-3 PUFA of marine origin limit diet-induced obesity in mice by reducing cellularity of adipose tissue. Lipids 39:1177-1185.

SAS institute Inc. 2011. SAS/STAT 9.2 User's Guide, 2nd ed. SAS institute Inc., Cary, NC.

Shaikh, S. R., B. D. Rockett, M. Salameh, and K. Carraway. 2009 Docosahexaenoic acid modifies the clustering and size of lipid rafts and the lateral organization and surface expression of MHC class I of EL4 cells. J. Nutr. 139:1632-1639.

Shao, X., M. Wang, X. Wei, S. Deng, N. Fu, Q. Peng, Y. Jiang, L. Ye, J. Xie, and Y. Lin. 2016. Peroxisome proliferator-activated recep- 
tor-gamma: Master regulator of adipogenesis and obesity. Curr. Stem Cell Res. Ther. 11:282-289.

Simopoulos, A. P. 2002. Omega-3 fatty acids in inflammation and autoimmune diseases. J. Am. Coll. Nutr. 21:495-505.

Sinclair, K. D. 2010. Declining fertility, insulin resistance and fatty acid metabolism in dairy cows: Developmental consequences for the oocyte and pre-implantation embryo. Acta Sci. Vet. 38(Suppl2):s545-s557.

Sumner, J. M., and J. P. McNamara. 2007. Expression of lipolytic genes in the adipose tissue of pregnant and lactating Holstein dairy cattle. J. Dairy Sci. 90:5237-5246.

Sumner-Thomson, J. M., J. L. Vierck, and J. P. McNamara. 2011. Differential expression of genes in adipose tissue of first-lactation dairy cattle1. J. Dairy Sci. 94:361-369.

Tai, C. C., C. Y. Chen, H. S. Lee, Y. C. Wang, T. K. Li, H. J. Mersamm, S. T. Ding, and P. H. Wang. 2009. Docosahexaenoic acid enhances hepatic serum amyloid A expression via protein kinase A-dependent mechanism. J. Biol. Chem. 284:32239-32247.

Tai, C. C., and S. T. Ding. 2010. N-3 polyunsaturated fatty acids regulate lipid metabolism through several inflammation mediators: mechanisms and implications for obesity prevention. J. Nutr. Biochem. 21:357-363.
Tersigni, C., F. Di Nicuolo, S. D'Tppolito, M. Veglia, M. Castellucci, and N. Di Simone. 2011. Adipokines: new emerging roles in fertility and reproduction. Obstet. Gynecol. Surv. 66:47-63.

van Straten, M., N. Y. Shpigel, and M. Friger. 2008. Analysis of daily body weight of high-producing dairy cows in the first one hundred twenty days of lactation and associations with ovarian inactivity. J. Dairy Sci. 91:3353-3362.

Wathes, D. C., A. M. Clempson, and G. E. Pollott. 2012. Associations between lipid metabolism and fertility in the dairy cow. Reprod. Fertil. Dev. 25:48-61.

Xiong, Y., N. Miyamoto, K. Shibata, M. A. Valasek, T. Motoike, R. M. Kedzierski, and M. Yanagisawa. 2004. Short-chain fatty acids stimulate leptin production in adipocytes through the $\mathrm{G}$ proteincoupled receptor GPR41. Proc. Natl. Acad. Sci. USA 101:10451050.

Zachut, M., A. Arieli, H. Lehrer, L. Livshitz, S. Yakoby, and U. Moallem. 2010. Effects of increased supplementation of n-3 fatty acids to transition dairy cows on performance and fatty acid profile in plasma, adipose tissue, and milk fat. J. Dairy Sci. 93:5877-5889. 